\title{
A Comparison of the Noise Characteristics of a Conventional Slat and Krueger Flap
}

\author{
Christopher J. Bahr, Florence V. Hutcheson†, Russell H. Thomas ${ }^{\dagger}$ \\ NASA Langley Research Center, Hampton, Virginia 23681 \\ Jeffrey A. Housman ${ }^{\ddagger}$ \\ NASA Ames Research Center, Moffett Field, California 94035
}

\begin{abstract}
An aeroacoustic test of two types of leading-edge high-lift devices has been conducted in the NASA Langley Quiet Flow Facility. The test compares a conventional slat with a notional equivalent-mission Krueger flap. The test matrix includes points that allow for direct comparison of the conventional and Krueger devices for equivalent-mission configurations, where the two high-lift devices satisfy the same lift requirements for a free air flight path at the same cruise airfoil angle of attack. Measurements are made for multiple Mach numbers and directivity angles. Results indicate that the Krueger flap shows similar agreement to the expected power law scaling of a conventional flap, both in terms of Strouhal number and fixed frequency (as a surrogate for Helmholtz number). Directivity patterns vary depending on the specific slat and Krueger orientations. Varying the slat gap while holding overlap constant has the same influence on both the conventional slat and Krueger flap acoustic signature. Closing the gap shows dramatic reduction in levels for both devices. Varying the Krueger overlap has a different effect on the data when compared to varying the slat overlap, but analysis is limited by acoustic sources that regularly present themselves in model-scale wind tunnel testing but are not present for full-scale vehicles. The Krueger cavity is found to have some influence on level and directivity, though not as much as the other considered parameter variations. Overall, while the spectra of the two devices are different in detail, their scaling behavior for varying parameters is extremely similar.
\end{abstract}

\section{Nomenclature}

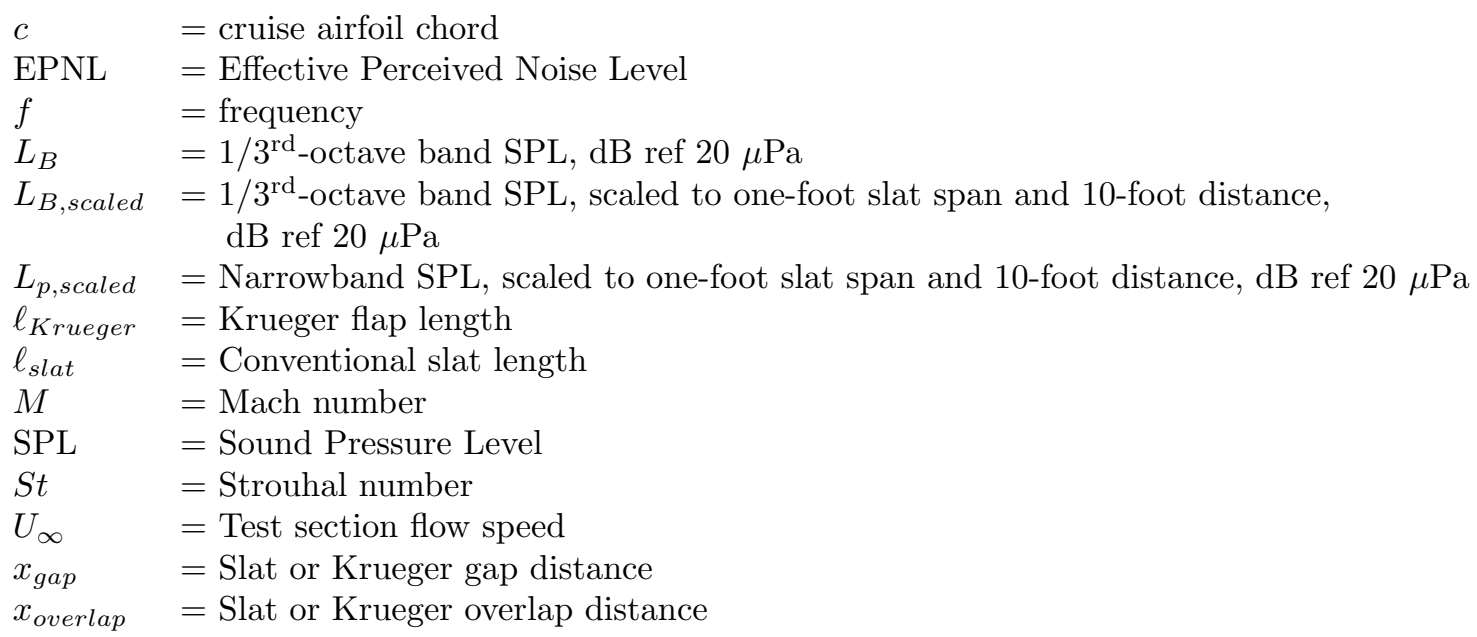

\footnotetext{
*Research Aerospace Engineer, Aeroacoustics Branch, MS 461, Senior Member AIAA, christopher.j.bahr@nasa.gov

†Senior Research Engineer, Aeroacoustics Branch, MS 461, Senior Member AIAA

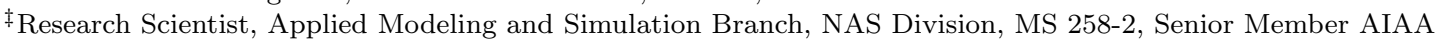




$$
\begin{array}{ll}
\alpha_{c} & =\text { Cruise airfoil angle of attack } \\
\alpha_{\text {slat }} & =\text { Conventional slat deployment angle } \\
\alpha_{\text {Krueger }} & =\text { Krueger flap deployment angle } \\
\alpha_{\infty} & =\text { Cruise airfoil free stream angle of attack } \\
\Delta L_{B, \text { scaled }} & =L_{B, \text { scaled,Conventional }}-L_{B, \text { scaled,Krueger }} \\
\delta_{\text {gap }} & =\text { Chord-normalized slat or Krueger gap distance, } x_{\text {gap }} / c \\
\delta_{\text {overlap }} & =\text { Chord-normalized slat or Krueger overlap distance, } x_{\text {overlap }} / c \\
\phi & =\text { MADA elevation angle, referenced to test section downstream direction } \\
\theta & =\text { Polar emission angle for slat noise source, referenced to test section upstream direction }
\end{array}
$$

\section{Introduction}

S commercial air traffic increases, the environmental impact of this increase must be mitigated through A reduction of the environmental footprint of individual aircraft. The NASA Environmentally Responsible Aviation (ERA) Project is part of the agency's continued efforts to do so, with simultaneous goals of $50 \%$ fuel burn reduction relative to the 2005 best in fleet, $75 \%$ nitrous oxide reduction below the Committee on Aviation Environmental Protection (CAEP) 6 standard, and $42 \mathrm{~dB}$ cumulative EPNL relative to the Stage 4 requirement! 1 Natural laminar flow (NLF) wings are one technology for improving fuel burn (and by association, reducing nitrous oxide emissions) through drag reduction. ${ }^{2}$ Krueger flaps offer a leadingedge high-lift device, which can shield NLF wings from insect fouling at low altitudes, in contrast to a conventional slat. However, as the structure and deployment mechanisms of a Krueger flap differ from those of a conventional slat, it is possible that the noise sources of the two differ ${ }^{3}$ The behavior of these sources must be studied to assess if NLF wing technology can simultaneously meet ERA fuel burn and noise goals. As part of ERA's broader efforts, an experiment that compares conventional slat and Krueger flap acoustic behavior was conducted and is now reported.

\section{Test Description}

This experiment was performed at the NASA Langley Research Center in the Quiet Flow Facility (QFF). The QFF is an anechoic, open jet wind tunnel equipped with a 2- by 3-foot rectangular nozzle. The facility can operate up to a Mach number of 0.17. The QFF is equipped with a Medium Aperture Directional Array (MADA), which is mounted on a rotating boom, allowing directional coverage of the model for a wide range of polar elevation angles (referenced to the downstream direction of the test section)! ${ }^{4}$ The azimuthal angle of the MADA can be manually varied but was not in this study.

\section{II.A. Test Hardware}

A pair of models were fabricated for this experiment. The intent of the experiment is to compare conventional slat and Krueger flap noise for models that could be, at least for one configuration, related for an equivalentmission. In this usage, equivalent-mission is defined such that both models have the same cruise airfoil profiles and flight operations, e.g., angles-of-attack (AoA) on approach, match. This experiment and matching process is involved in the broader objective of implementing a noise model for Krueger flaps, which is documented by Guo et al ${ }^{[5}$ Note that this experiment only addresses the two dimensional noise sources, neglecting three dimensional Krueger flap bracket noise sources, which may be dominant for many flight conditions ${ }^{6}$

Two models were necessary for this experiment, as the Krueger flap deploys from the pressure side of the cruise airfoil while the conventional slat deploys from the leading edge of the cruise airfoil, leading to different main element airfoil profiles. Additionally, the Krueger model required a pressure side cavity cutout to evaluate the potential influence of a notional Krueger stowage cavity on the model aerodynamics and aeroacoustics. The Krueger model cavity could be closed with a plate matching the cruise airfoil contour. Due to the scale of this test, the cavity was extremely simplified from what would be present on a full-scale aircraft. Both models were equipped with static pressure ports and Kulite dynamic pressure transducers. The aerodynamic pressure measurements allowed for sectional lift calculation and comparison with ReynoldsAveraged Navier Stokes (RANS) simulations for validation of effective free stream AoA calculations. 
A well-studied model, the $30 \mathrm{P} 30 \mathrm{~N}$, was selected for the reference conventional slat model ${ }^{7}$ The stowed, cruise airfoil associated with the $30 \mathrm{P} 30 \mathrm{~N}$ work provided a consistent basis for model design. The cruise airfoil chord was reduced from $c=18$ inches to $c=16.7$ inches in an effort to reduce the turning of the QFF test section jet flow induced by these high-lift models. This reduction also matched the conventional slat model's main element chord to that of previous high-lift model studies in the QFF $\stackrel{8}{7}$ A photograph of the Krueger model installation is shown in Fig. 1a, with a schematic of the conventional slat installation and measurement setup shown in Fig. 1b.

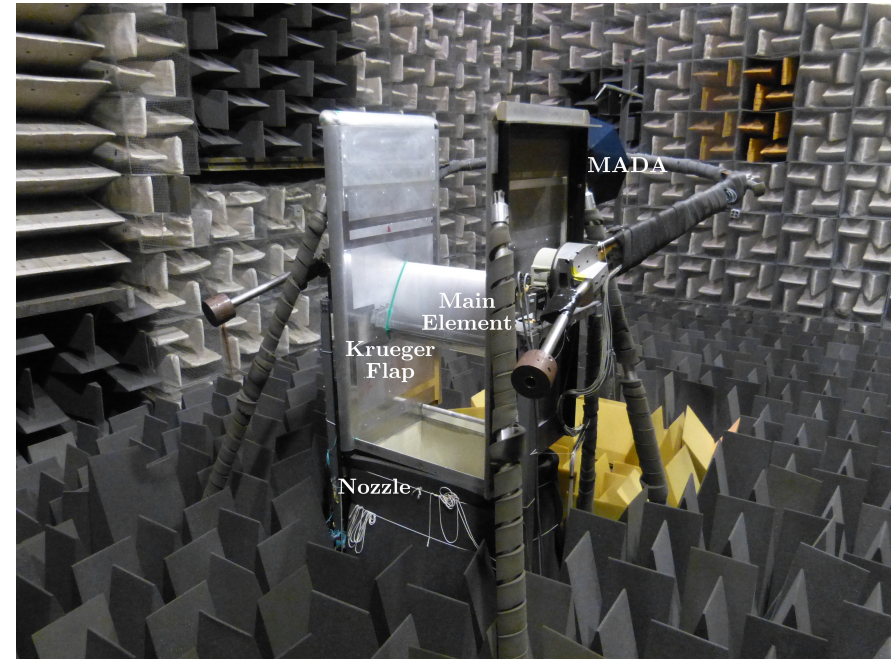

(a) Krueger installation photograph

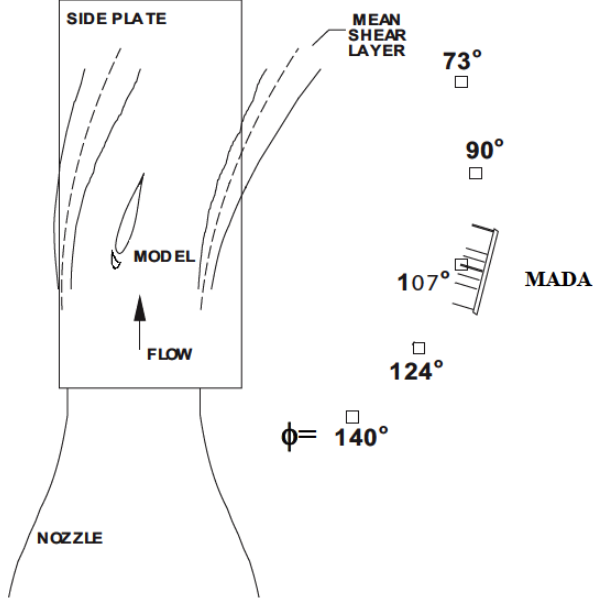

(b) Measurement locations (slat)

Figure 1. High-lift model installation and acoustic instrumentation in QFF. Note that the origin for $\phi$ is determined by the center of rotation of the MADA boom, not the slat.

The conventional slat design used in this experiment has some differences when compared to the baseline slat from the recent BANC Workshop series. Some cove modifications were included in the design, which were based on changes to the model in recent work with slat cove fillers $\frac{9}{9}$ Further minor modifications were incorporated for practical machining purposes. The as-built geometry of the conventional slat is shown in Fig. 2a. As with previous high-lift studies in the QFF, the model was fabricated with a stowed flap to mitigate open jet turning effects $[\overline{8}$ This significantly reduces the achievable lift of the installed model, but allows the noise generation mechanisms of the leading edge device to be studied independently of the flap noise.

The Krueger flap used in this work was designed through an extensive RANS campaign documented in a companion paper by Akaydin et al $!^{10}$ as part of a slat noise study. The overall study also includes computational efforts by Housman and Kiris ${ }^{11}$ Summarizing the design process, a chain of Computational Fluid Dynamics (CFD) simulations was used to link the conventional slat configuration within the QFF to the Krueger flap configuration within the QFF. First, the conventional slat model was simulated in the QFF open jet flow for two cruise airfoil AoAs, $\alpha_{c}=27^{\circ}$ and $\alpha_{c}=33^{\circ}$. These corresponded to the two main element airfoil AoAs used in previous work ${ }^{[8]}$ The simulations were conducted for slat deployment angles of $\alpha_{\text {slat }}=10^{\circ}, \alpha_{\text {slat }}=20^{\circ}$, and $\alpha_{\text {slat }}=30^{\circ}$, all with a stowed flap. A series of simulations were then run in free air for these three slat deployment angles with the flap deployed. The lift and pressure coefficient profiles about the slat and leading edge region of the model were compared between the installed and free air simulations to find the free air equivalent AoAs for the two installed AoAs. The free air equivalent of the QFF-installed $\alpha_{c}=27^{\circ}$ was found to be $\alpha_{\infty}=2^{\circ}$, while that for the QFF-installed $\alpha_{c}=33^{\circ}$ was found to be $\alpha_{\infty}=4.5^{\circ}$. Note that matching only the slat aerodynamics and neglecting the leading edge region of the model led to respective equivalent free air AoAs of $\alpha_{\infty}=4.5^{\circ}$ and $\alpha_{\infty}=8^{\circ}$, consistent with the previous QFF slat noise study ${ }^{8}$

A Krueger flap was then designed to match the overall model lift at these free air AoAs with a deployed trailing flap. The as-built geometry of this Krueger flap is shown in Fig. 2b. The Krueger deployment details for the QFF-installed configuration (gap, overlap, angle) were then determined via a final set of CFD runs for a stowed trailing flap configuration in the open jet facility. Table 1 summarizes these details for the 
$\alpha_{c}=27^{\circ}$ experiments. Fig. 2c defines the deployment parameters for the conventional slat model. Note that this figure shows a positive overlap value. Negative overlap indicates the slat trailing edge is downstream of the main element leading edge. The Krueger flap deployment parameters function similarly, although $\alpha_{\text {Krueger }}$ is defined from the stowed Krueger position and thus, has an angle reference of the local cruise airfoil pressure side profile slope at the leading edge of the Krueger cavity.

Table 1. Krueger deployment settings for equivalent-mission conventional slat settings. For all baseline conventional slat angles, $\delta_{\text {gap }}=3.08 \%$ and $\delta_{\text {overlap }}=2.66 \%$.

\begin{tabular}{|r||r|r|r|}
\hline $\begin{array}{c}\text { slat angle } \\
\alpha_{\text {slat }}\end{array}$ & $\begin{array}{r}\text { Krueger angle } \\
\alpha_{\text {Krueger }}\end{array}$ & $\begin{array}{r}\text { Krueger gap } \\
\delta_{\text {gap }}\end{array}$ & $\begin{array}{c}\text { Krueger overlap } \\
\delta_{\text {overlap }}\end{array}$ \\
\hline \hline $10^{\circ}$ & $131^{\circ}$ & $1.12 \%$ & $0.20 \%$ \\
\hline $20^{\circ}$ & $127^{\circ}$ & $1.12 \%$ & $0.20 \%$ \\
\hline $30^{\circ}$ & $124^{\circ}$ & $1.54 \%$ & $0.78 \%$ \\
\hline
\end{tabular}

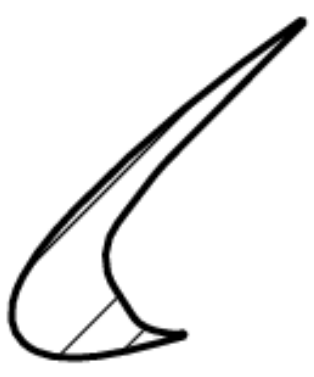

(a) Conventional slat

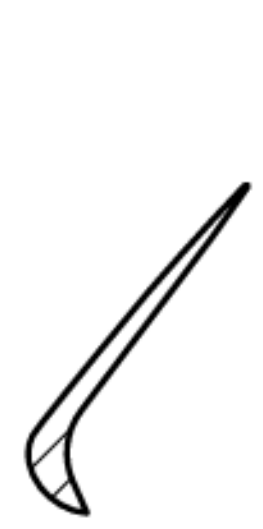

(b) Krueger flap

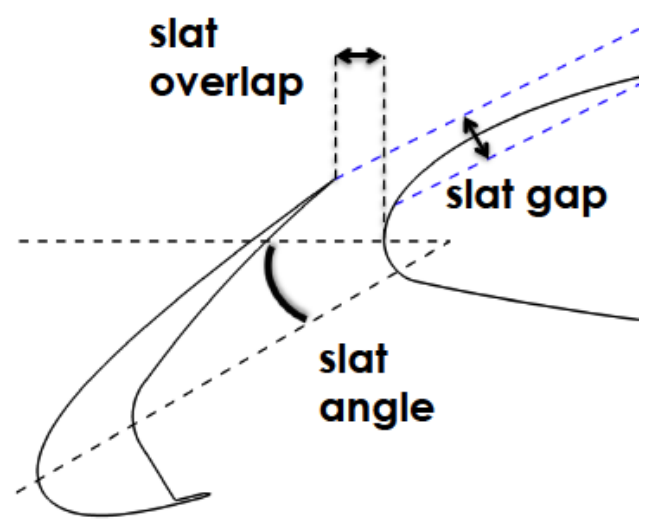

(c) Slat deployment parameters

Figure 2. High-lift device shapes and deployment parameter definitions for the conventional slat. The conventional slat angle $\alpha_{\text {slat }}$ is defined as the total rotation about the slat trailing edge from the stowed orientation, with an effective reference of the model chord line. The Krueger flap angle $\alpha_{\text {Krueger }}$ is also defined this way, with an effective reference of the local airfoil surface slope at the Krueger cavity leading edge.

\section{II.B. Data Acquisition and Processing}

Acoustic data were acquired using the MADA at elevation angles of $\phi=73^{\circ}, 90^{\circ}, 107^{\circ}, 124^{\circ}$, and $140^{\circ}$, always on the model pressure side. These values correspond to a variety of emission angles, depending on the test section speed, ambient conditions and the model AoA. The emission angles for an example acquisition are summarized in Table 2, although these relations could vary by a degree or so depending on ambient conditions. Emission angles were computed using the retarded angle relationships of Amiet $\frac{12}{, 2}$ prior to being re-referenced to the test section upstream direction. Note that the $\phi=73^{\circ}$ relationship is not shown, and the data are not presented in this paper. At this angle, uncertainty in the shear layer position for various configurations leads to greater variability in the shear layer correction, $\frac{13}{,}$ and the results become difficult to assess.

The MADA consists of 41 B\&K model 4138, 1/8-inch microphones projecting from an acoustically treated frame. The array pattern is an extension of the Small Aperture Directional Array $[\sqrt[8]{14}$ adding an additional irregular ring of microphones. The employed microphone shading scheme maintains a constant beamwidth (when applying conventional beamforming) of 1 foot for the frequency band spanning from $5 \mathrm{kHz}$ to $40 \mathrm{kHz}$.

Data were acquired at a sampling rate of 200,000 samples/sec for 60 seconds, yielding 1464 non-overlapping data blocks with a length of 8192 samples each. All channels were filtered with a passband between 300 $\mathrm{Hz}$ and $90 \mathrm{kHz}$. A Hamming window was applied to each block of data prior to the calculation of narrowband auto- and cross-spectra. The resultant spectral frequency resolution from this sampling rate and block 
Table 2. Relationships between MADA elevation $(\phi)$ and slat emission $(\theta)$ angles for varying Mach number, model AoA of $27^{\circ}$ in QFF test section. $\phi$ is referenced as given in Fig. 1. while $\theta$ is referenced to the upstream direction in the test section with origin located at the center span of the equivalent cruise airfoil profile.

\begin{tabular}{|r||r|r|r|r|r|}
\hline \multicolumn{1}{|c||}{} & \multicolumn{5}{c|}{$\theta$} \\
\hline \multicolumn{1}{|c||}{} & $M=0.09$ & $M=0.11$ & $M=0.13$ & $M=0.15$ & $M=0.17$ \\
\hline \hline $140^{\circ}$ & $54.0^{\circ}$ & $53.8^{\circ}$ & $53.7^{\circ}$ & $53.6^{\circ}$ & $53.5^{\circ}$ \\
\hline $124^{\circ}$ & $71.7^{\circ}$ & $71.4^{\circ}$ & $71.1^{\circ}$ & $70.8^{\circ}$ & $70.6^{\circ}$ \\
\hline $107^{\circ}$ & $89.8^{\circ}$ & $89.6^{\circ}$ & $89.4^{\circ}$ & $89.2^{\circ}$ & $89.0^{\circ}$ \\
\hline $90^{\circ}$ & $107.4^{\circ}$ & $107.5^{\circ}$ & $107.6^{\circ}$ & $107.6^{\circ}$ & $107.7^{\circ}$ \\
\hline
\end{tabular}

length is $24.4 \mathrm{~Hz}$. The data were then processed using the DAMAS algorithm. $\frac{15}{15}$ To accelerate processing, 7 adjacent spectral bins were summed in the computed cross-spectral matrix prior to processing, yielding narrowband DAMAS results for 585 frequencies for every test point. Steering vectors were computed for the center bin frequencies of these narrowband summation bounds. These steering vectors accounted for free shear layer refraction, atmospheric attenuation and instrumentation directivity ${ }^{16}$ DAMAS was run for 500 iterations in a varying two-dimensional sweep pattern, and integrated levels were tracked to ensure convergence. Resultant DAMAS narrowband data were then summed into $1 / 3^{\text {rd }}$-octave bands as necessary.

The summation region for calculating integrated levels was specified around the model leading edge such that slat/Krueger noise sources were isolated from other facility and model/facility interaction noise sources. The need for deconvolution is illustrated in Fig. 3. where the conventional beamforming output in Fig. $3 \mathrm{a}$ shows sidewall junction contamination of the leading edge noise source. Fig. 3b, which shows acoustic levels referenced to the MADA center, demonstrates the ability of deconvolution to isolate the acoustic sources of interest from extraneous installation noise sources. Note that the scale of the experiment with respect to the array precludes the isolation of individual components of the slat such as the gap and cove.

For subsequent spectral plots, the integrated levels are scaled to a per-foot slat span from the full width of the integration bounds. They are also scaled to a common 10 foot emission distance referenced from the center span point of the equivalent cruise (stowed slat/Krueger) configuration leading edge of $(x, y)=(0,0)$ in Fig. 3. While somewhat non-intuitive, this point is a common geometric reference between the conventional slat and Krueger flap models.

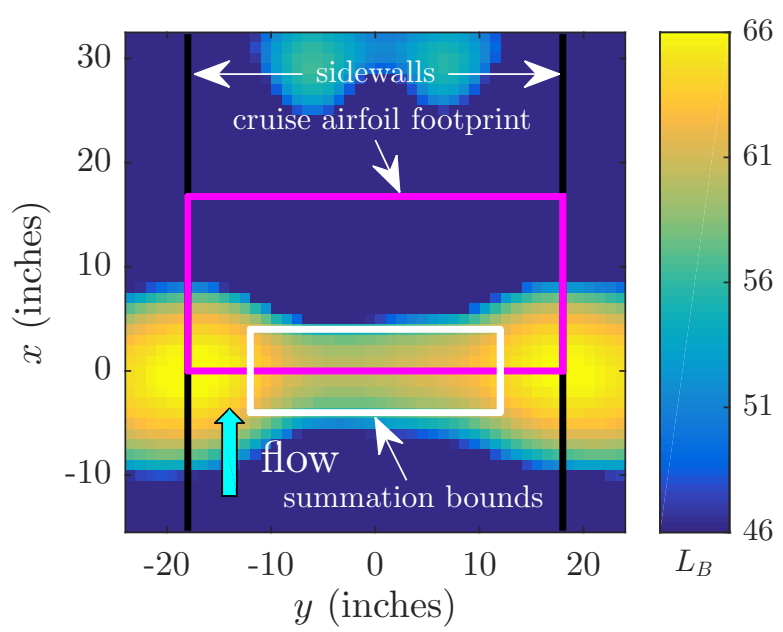

(a) Conventional beamforming

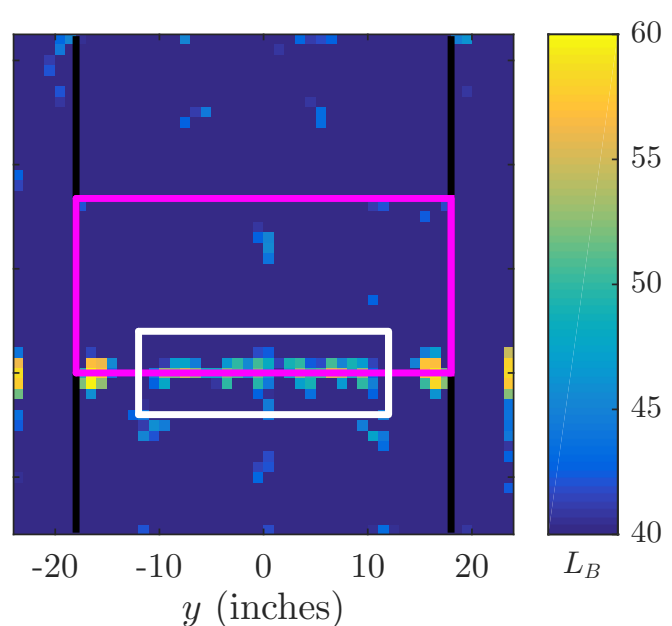

(b) DAMAS output

Figure 3. $20 \mathrm{kHz} 1 / 3^{\text {rd }}$-octave band MADA output for the Krueger flap configuration shown in Fig. 1a. Data are acquired at a Mach number of $M=0.17$ and a MADA elevation angle of $\phi=124^{\circ}$. Flow is from bottom-to-top of the plots. The footprint of the equivalent cruise model for both the conventional slat and Krueger is denoted with the magenta boundary. The summation region is denoted with the white boundary. Test section sidewalls are denoted with black lines. 


\section{Results - Matched Run Conditions}

While the conventional slat and Krueger flap were evaluated at a variety of run conditions, those which had the design equivalent-mission parameters are discussed first. As mentioned, the equivalent-mission parameters were evaluated to provide Krueger locations and angles to match six conventional slat configurations. These conventional slat configurations were $\alpha_{\text {slat }}=10^{\circ}, \alpha_{\text {slat }}=20^{\circ}$, and $\alpha_{\text {slat }}=30^{\circ}$ deployment angles for model AoAs of $\alpha_{c}=27^{\circ}$ and $\alpha_{c}=33^{\circ}$. Discussion in this paper is limited to the $\alpha_{c}=27^{\circ}$

data. The $\alpha_{c}=33^{\circ}$ data were observed to trend with the results of Mendoza et al ${ }^{8}$ when compared to the $\alpha_{c}=27^{\circ}$ data. As in the reference, increasing $\alpha_{c}$ shows a reduction in level for various parts of the spectrum.

\section{III.A. Baseline spectra}

The first matched configuration addressed is that of the baseline conventional slat deployment. Here the slat is deployed at the baseline $30 \mathrm{P} 30 \mathrm{~N}$ design configuration of $\alpha_{\text {slat }}=30^{\circ}, \delta_{\text {gap }}=3.08 \%$ and $\delta_{\text {overlap }}=2.66 \%$. This is compared to the equivalent-mission Krueger deployment configuration of $\alpha_{\text {Krueger }}=124^{\circ}, \delta_{\text {gap }}=1.54 \%$ and $\delta_{\text {overlap }}=0.78 \%$. Note that for all cases, the deconvolution maps for data below $3 \mathrm{kHz}$ and above 60 $\mathrm{kHz}$ become difficult to interpret, and thus, integrated levels are likely unreliable. Results are included in these bands for qualitative trend analysis. Additionally, Mach 0.09 data do not always scale as expected and may be approaching a "noise floor" for the analysis.

Integrated spectra are plotted in Fig. 4. The conventional slat spectra in Fig. 4a show features common to many slat noise experiments. Specifically, multiple tonal peaks are present at lower frequencies contaminating the broadband spectral component 17 The low frequency tones are often attributed to low Reynolds number effects in experiments and are not observed at full-scale conditions. $\frac{18}{18}$ These tones are not fully understood, but since they do not appear to occur at full-scale they undesirably influence the data of interest. Various trip configurations were applied to the slat to see how the tones might be altered or reduced. The trips altered individual tone levels, but had no influence on the overall characteristics of the tone spectra.

Minor perturbations to the test section inflow condition (e.g., an individual lightly pressing a hand into the test section shear layer near the inlet) were found to have an audible influence on tone frequency and amplitude, but inconsistently so. Significantly increasing the inflow turbulence levels disrupted the tones, but also changed the entire model's aeroacoustic behavior. Adding a thin trailing edge extension, similar to what Mendoza et al. did to assess slat trailing edge bluntness effects,$\frac{8}{,}$ significantly reduced the strength of the tones for some configurations. For these configurations, it is assumed that the trailing edge extension disrupts the feedback mechanisms that are hypothesized to generate the tones 7 [19 However, the extension did not influence the tones for every configuration, and its installation added noticeable broadband noise, so it was not applied to the model for the majority of the experiment. High frequency tones, as observed in other slat noise measurements $20[21$ and are attributed to vortex shedding from the slat trailing edge in conjunction with a resonance mechanism, were not seen for this conventional slat configuration.

The Krueger flap spectra, plotted in Fig. 4b, show similar overall characteristics to the conventional slat spectra for low- to mid-frequencies. However, the distribution of the low frequency tones in the Krueger data has shifted to lower frequencies compared to the conventional slat. Also, the tone magnitudes are reduced. Similar treatments were applied to the Krueger flap to study their influence on the low frequency tones, and similar behavior was observed. Unlike the conventional slat, this Krueger model does exhibit a trailing edge shedding peak at high frequencies. Due to model fabrication limitations, the Krueger trailing edge is significantly thicker than it should be for a true scale model, so the shedding peak influences data in an undesirable way when full-scale analysis is desired. Various trailing edge treatments were tested to evaluate and remove the shedding peak, allowing isolation of the data of interest. Thickening the trailing edge on its suction side confirmed the expected Strouhal scaling of the shedding frequency. Thin trailing edge extensions, both straight and serrated, mitigated this shedding peak in addition to altering the low frequency tones. However, as with the conventional slat model, the installation of trailing edge extensions added significant broadband noise, so no extension was applied to the model for the majority of the experiment. Note that a very sharp tone is sometimes embedded in the frequency range of the trailing edge shedding peak. This tone was found to be caused by a model pressure tap under certain conditions. Once the issue was discovered, the tap was taped over and the tone eliminated for the remainder of the experiment. 


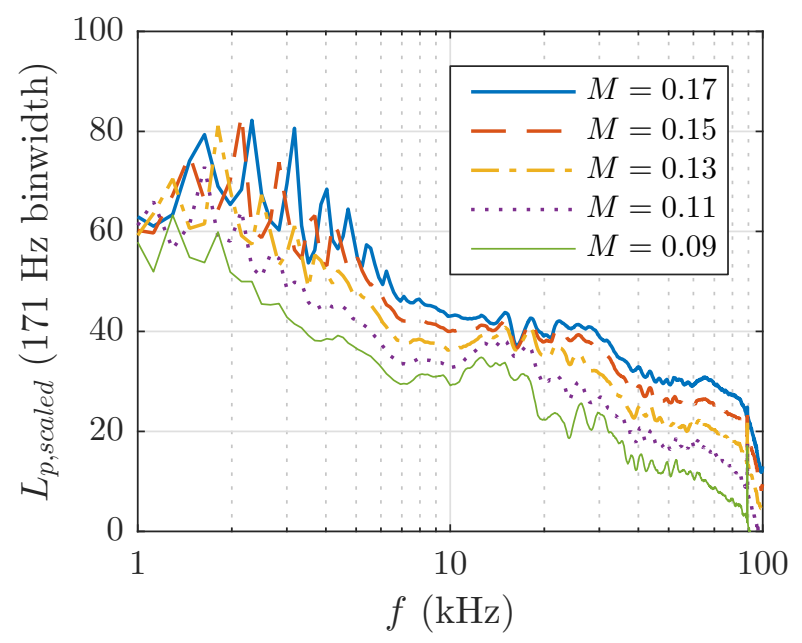

(a) Conventional slat

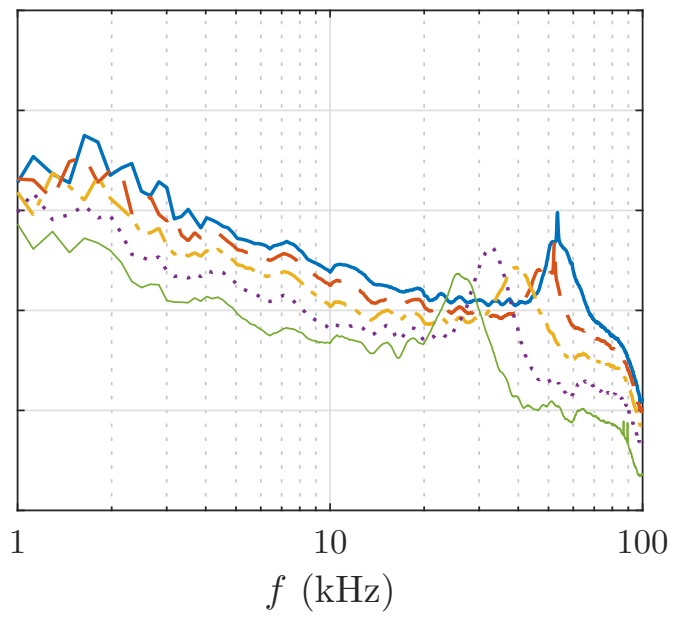

(b) Krueger flap

Figure 4. DAMAS narrowband integrated spectra for both conventional and Krueger leading edge devices for varying Mach number, MADA elevation angle of $\phi=124^{\circ}$. The conventional slat is deployed at $\alpha_{\text {slat }}=30^{\circ}$. The Krueger flap is at its equivalent deployed configuration.

\section{III.B. Non-dimensional analysis}

Spectra are further scaled by test section Mach number and plotted as a function of Strouhal number in Fig. 5. Previous work suggests that acoustic levels should be scaled by a Mach power law of $M^{4.5}$ when evaluated as a function of Strouhal number, indicating a combination of monopoles and edge noise sources ${ }^{22}$ The length of the device, here defined as its greatest dimension, is used rather than its chord due to the potential for different definitions of chord between conventional slats and Krueger flaps. The length of the conventional slat is $\ell_{\text {slat }}=2.54$ inches. The length of the Krueger flap is $\ell_{\text {Krueger }}=2.63$ inches.

The conventional slat noise scaling is shown in Fig. $5 \mathrm{a}$. Scaling by a Mach power of 4.5 provides reasonable collapse for all of the broadband data above $S t=13$, and all but the lowest Mach number curve above $S t=10$. Power laws of 4 and 5 perform no better when considering the whole range. The spectra below this range but above $S t=6$ appear as a mixture of both the broadband and tonal components of the spectra. The low frequency tones dominate the spectra below $S t=6$. The lowest-frequency tone in the data occurs at $S t=0.86$, outside of the plotted range. The subsequent tones follow at $S t$ multiples of this fundamental. No common power law collapse of the tone levels is observed.

The Krueger flap noise scaling is shown in Fig. 5b. Scaling by a Mach power of 4.5 provides better collapse for these spectra than for the conventional slat data, at least for the Strouhal number range above any influence of the low-frequency tones and below the blunt shedding peaks. The lowest-frequency tone in the data occurs at $S t=0.62$, again outside of the plotted range. The subsequent tones follow at $S t$ multiples of the fundamental. As with the conventional slat data, no common power law for tone levels is observed. The trailing edge shedding peak from the Krueger flap shows reasonable frequency collapse if one allows for some minor variability in the scaling of local trailing edge flow speed with respect to test section speed. An alternate Strouhal definition using a length scale of the Krueger flap trailing edge thickness of 0.02 inches and the local trailing edge flow speed from RANS results $\frac{10}{10}$ for $M=0.17$ yields the expected Strouhal number of slightly greater than 0.2 for the shedding peak ${ }^{[8}$ No level collapse is observed. As the peak levels of these tones do not show any consistent Mach behavior for the unscaled spectra in Fig. $4 \mathrm{~b}$, no level collapse should be expected for any Mach power law.

Slat noise has multiple source mechanisms, and a simple global collapse of the spectra for a single Mach power and Strouhal definition should not be expected. Some portions of the spectrum should show similarity based on the Helmholtz number $\stackrel{23] 24}{24}$ herein defined as $2 \pi \times M \times S t$, rather than the Strouhal number. For this experiment, length scales were invariant. The QFF draws air from the facility exterior, so the speed of sound is not a controllable independent parameter. It is usually nearly constant for a Mach and directivity sweep on a given model configuration. This means that for this experiment any data collapse based on Helmholtz number would also occur on a fixed-frequency basis. Since no discussion is presented relating 


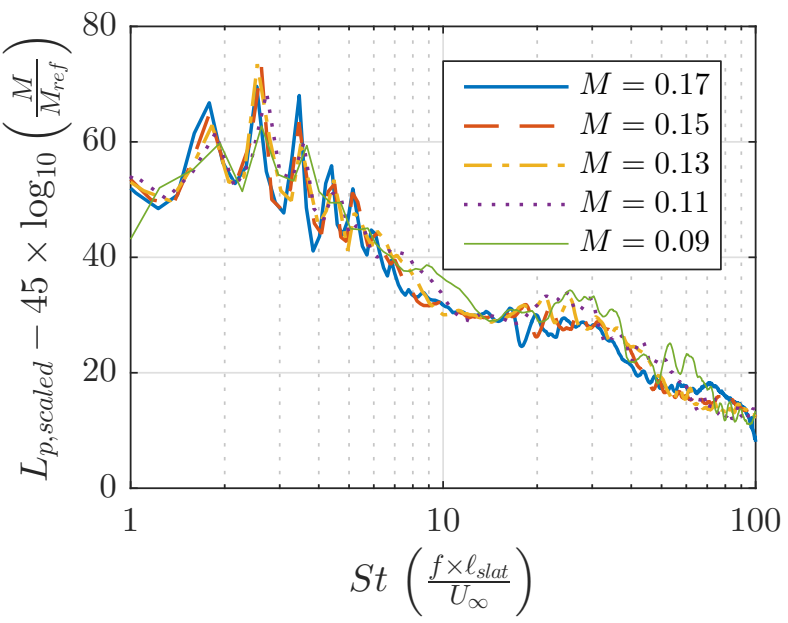

(a) Conventional slat

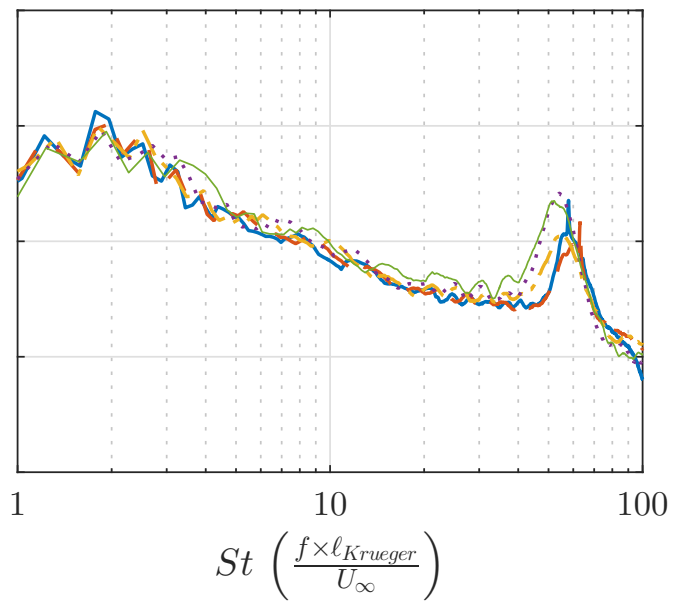

(b) Krueger flap

Figure 5. Mach-scaled narrowband spectra as a function of Strouhal number for both conventional and Krueger leading edge devices for a MADA elevation angle of $\phi=124^{\circ}$. The reference Mach number is $M_{r e f}=0.09$.

spectral features to a given Helmholtz number, data collapse as a function of fixed frequency is shown in Fig. 6.

Two power laws are considered for frequency collapse, $M^{4}$ and $M^{6}$. These are not presented to analyze absolute source behavior in terms of monopoles and dipoles, but to bound the reasonable regimes of spectral collapse for assumed source types. Any region that should collapse for $M^{5}$ due to edge scattering, for example, would be visible as a transition between $M^{4}$ and $M^{6}$. Anything with a slightly higher power, say $M^{7}$, should appear close to collapse for $M^{6}$. The conventional slat shows limited spectral collapse for $M^{4}$ in Fig. 6a in the region of the spectrum between $10 \mathrm{kHz}$ and $20 \mathrm{kHz}$, before transitioning to $M^{6}$ scaling at frequencies above $20 \mathrm{kHz}$ and frequencies between $7 \mathrm{kHz}$ and $10 \mathrm{kHz}$ when neglecting the $M=0.09$ data (Fig. 6c). Low frequency tones contaminate the data sufficiently to impede further analysis of this low frequency scaling. The high frequency scaling also collapses well for an $M^{7}$ power law (not shown here) as predicted by Guo for two dimensional slat noise. 23

The $M^{4}$ scaling of the Krueger is shown in Fig. 6b. This shows some collapse for frequencies above approximately $15 \mathrm{kHz}$. The data would appear to suggest that if the shedding peak were suppressed this may continue into the shedding frequency band. Unfortunately the shedding peaks are sufficiently broad to impede any further analysis of this behavior. The $M^{6}$ scaling of the Krueger is shown in Fig. 6d. Spectral collapse is seen for frequencies ranging from where the low frequency tones cut off to approximately $10 \mathrm{kHz}$, prior to transitioning to the $M^{4}$ scaling at $15 \mathrm{kHz}$. Spectral collapse is also seen at frequencies beyond the band contaminated by shedding peaks.

For the available data, scaling does appear similar between the high-lift devices. While comparison is limited at low frequencies by conventional slat tones and at high frequencies by the Krueger shedding peak, a significant portion of the mid-band spectrum scales with $M^{6}$ for both devices. The higher portion of the comparable middle bandwidth of the two devices scales as $M^{4}$ prior to contamination by the Krueger shedding peak, though this collapse appears better and broader for the Krueger than the conventional slat. At high frequencies the conventional slat noise scales well with $M^{6}$. The limited band of Krueger data above the shedding peaks appears to scale similarly.

\section{III.C. Directivity}

Analysis of directivity as a function of $\phi$ is plotted in Fig. 7. For the remainder of this report, discussion is limited to a flow condition of $M=0.17$. However, for this section, the directivities of all three $\alpha_{c}=27^{\circ}$ slat angle configurations are addressed. As a reminder, while $\alpha_{\text {slat }}$ is the only parameter varied here for the conventional slat, $\delta_{\text {gap }}$ and $\delta_{\text {overlap }}$ are varied in addition to $\alpha_{\text {Krueger }}$ when the configuration transitions 


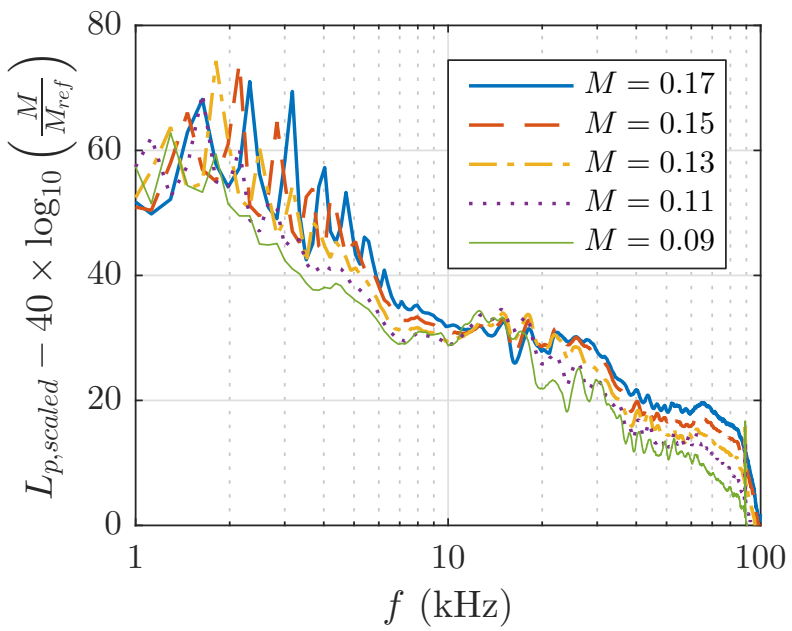

(a) Conventional slat, $M^{4}$ scaling

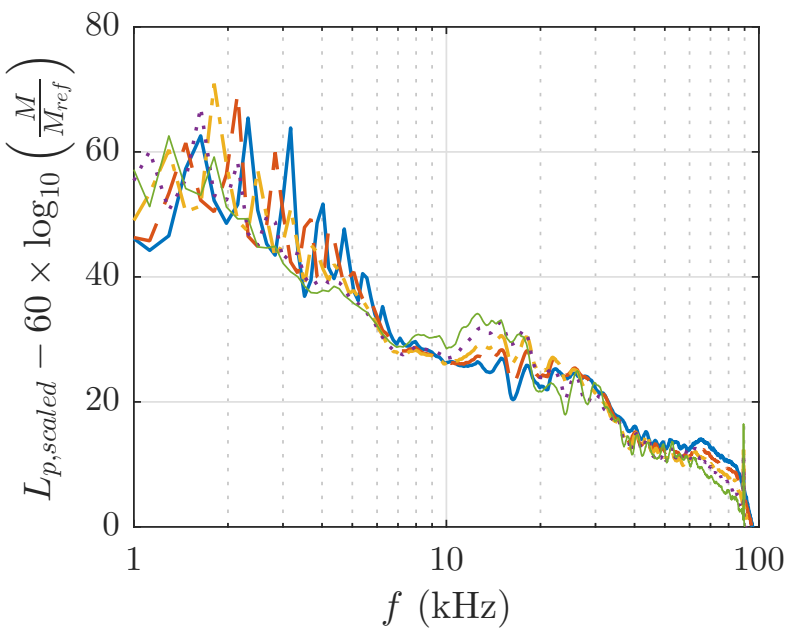

(c) Conventional slat, $M^{6}$ scaling

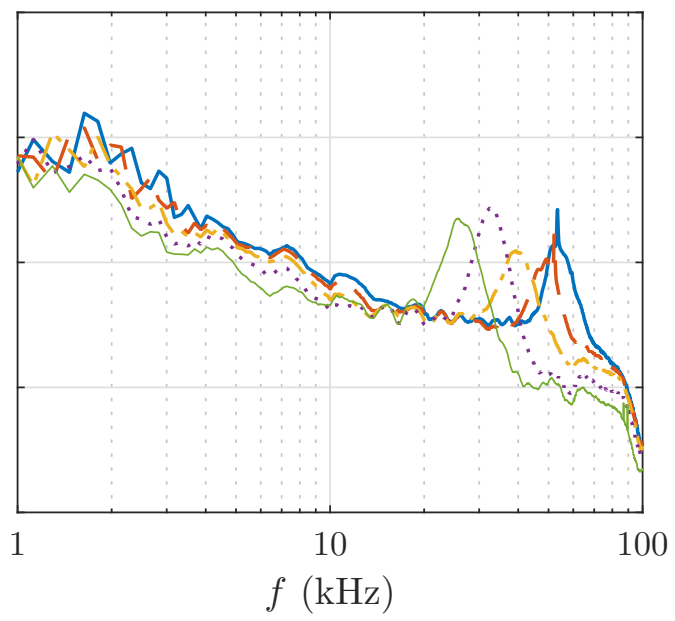

(b) Krueger flap, $M^{4}$ scaling

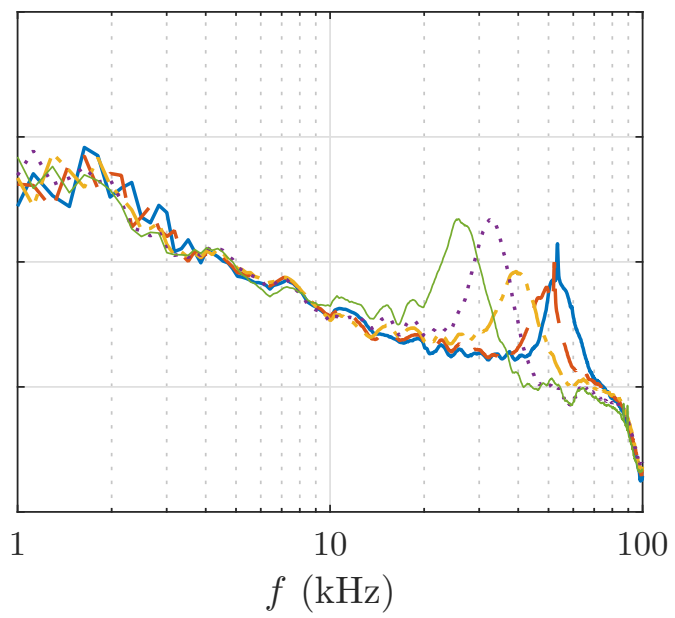

(d) Krueger flap, $M^{6}$ scaling

Figure 6. Mach-scaled narrowband spectra as a function of fixed frequency for both conventional and Krueger leading edge devices for a MADA elevation angle of $\phi=124^{\circ}$. The reference Mach number is $M_{r e f}=0.09$.

between the $20^{\circ}$ and $30^{\circ}$ equivalents. Thus, while the data allow analysis of the influence of conventional slat angle as an isolated parameter, such analysis of the Krueger is more limited.

The conventional slat directivity for $\alpha_{\text {slat }}=10^{\circ}$ is shown in Fig. 7a. Narrowband levels in the measurement are at a maximum forward of the model $\left(\phi=140^{\circ}\right)$ and show a decreasing trend toward the model aft $\left(\phi=90^{\circ}\right)$, although for low- to mid-range frequencies the $\phi=140^{\circ}$ and $\phi=124^{\circ}$ data are approximately equal. This trend is in agreement with the overall behavior shown by Mendoza et al. 8 The spectral shape of the data shows significantly more ripple as aft angles are approached. Some of the low frequency tones are nearly omnidirectional across this directivity range, although others show roll-off toward aft angles. Note that the frequencies and levels of the tones change as a function of $\alpha_{\text {slat }}$. The Krueger data in Fig. $7 \mathrm{~b}$ behave similarly. Low frequency tones are nearly omnidirectional and the broadband portion of the spectra peaks forward of the model and decreases toward its aft. The shedding peak shows a strong directivity, with a maximum at $\phi=124^{\circ}$ and showing some reduction forward of the model and significant reduction toward its aft. The Krueger data show less spectral ripple increase as the angle shifts toward the aft direction, in contrast to the conventional slat.

The conventional slat directivity for $\alpha_{\text {slat }}=20^{\circ}$, shown in Fig. 7c begins to diverge from the previous results. While the behavior of the low frequency tones and spectral shape is similar to that of $\alpha_{\text {slat }}=10^{\circ}$, 


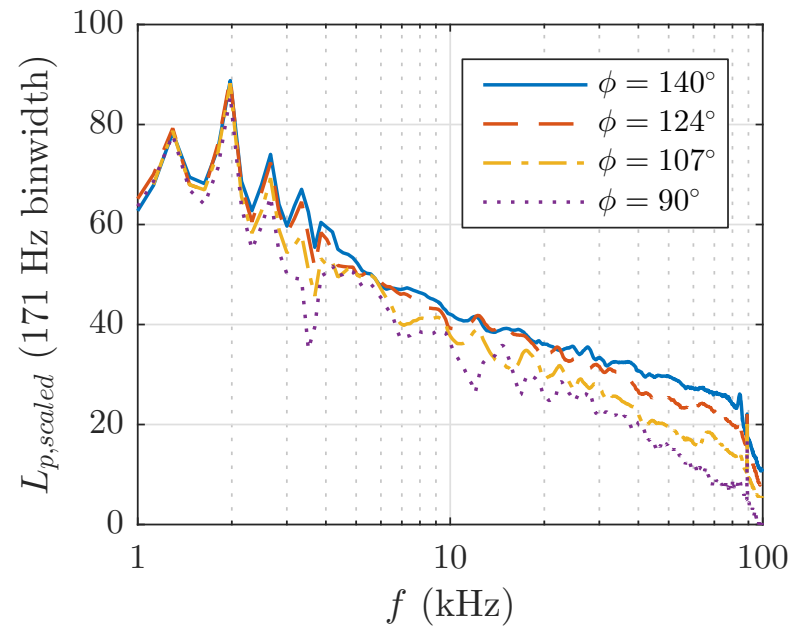

(a) Conventional slat, $\alpha_{\text {slat }}=10^{\circ}$

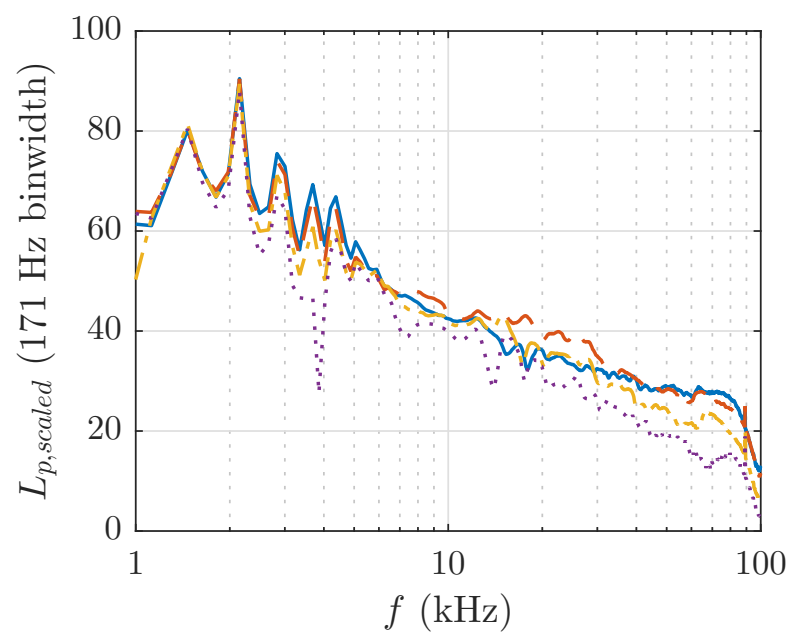

(c) Conventional slat, $\alpha_{\text {slat }}=20^{\circ}$

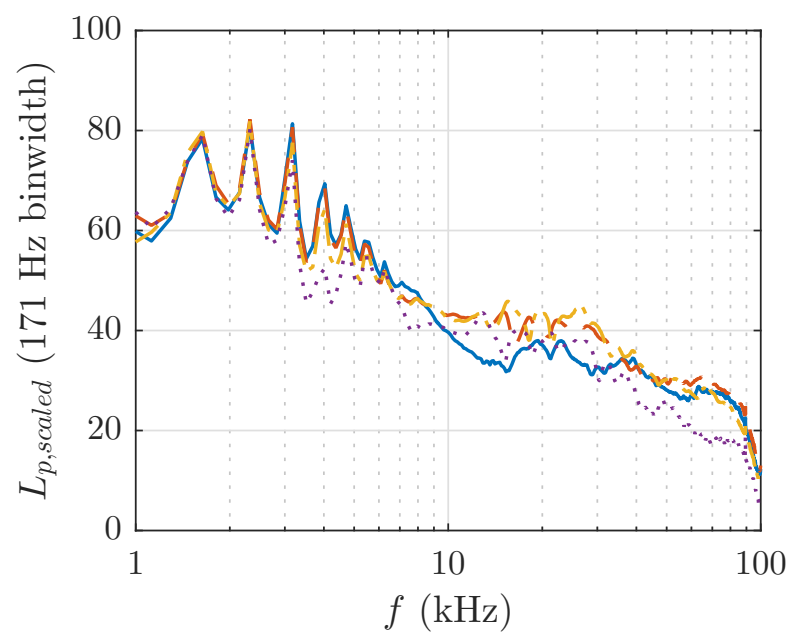

(e) Conventional slat, $\alpha_{\text {slat }}=30^{\circ}$

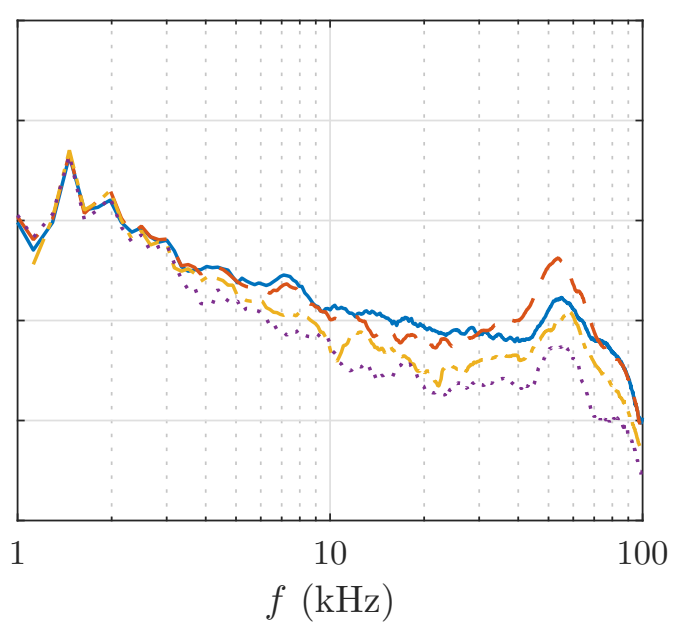

(b) Krueger flap, $10^{\circ}$ equivalent

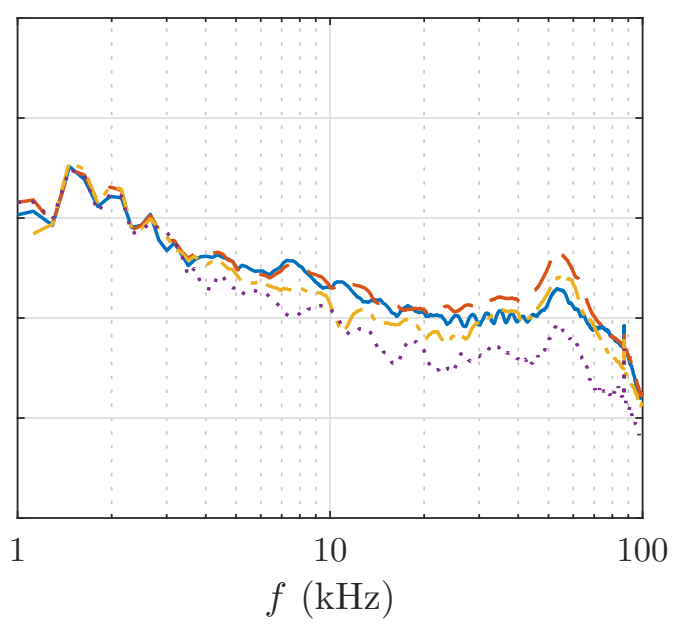

(d) Krueger flap, $20^{\circ}$ equivalent

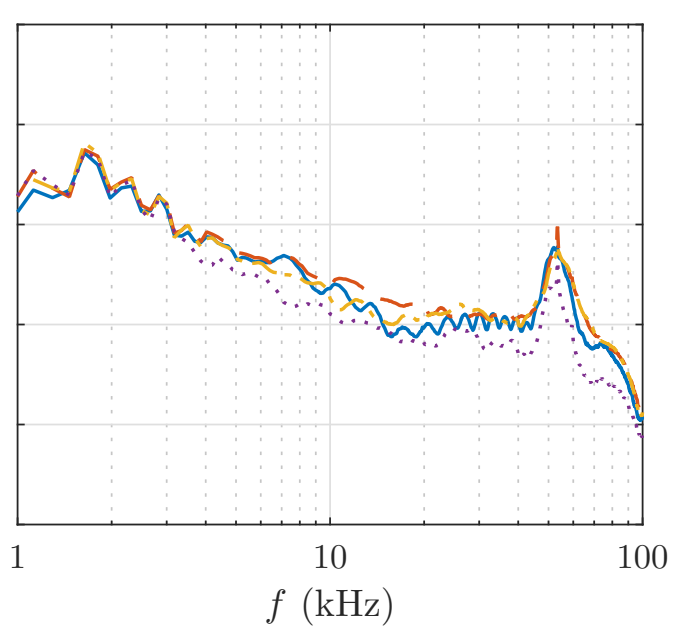

(f) Krueger flap, $30^{\circ}$ equivalent

Figure 7. Matched-mission directivity, $M=0.17$. The angle $\phi$ is referenced from the downstream direction. 
the directivity shows a maximum at $\phi=124^{\circ}$ for much of the analysis bandwidth, with reduction progressing toward $\phi=90^{\circ}$. For the Krueger in Fig. 7d a similar directivity trend is observed when compared to the slat in Fig. $7 \mathrm{c}$ although more spectral ripple is evident in the forward angle data. The shedding peak behavior is similar, and while the peak level for $\phi=140^{\circ}$ is now lower than that for $\phi=107^{\circ}, \phi=124^{\circ}$ is still the maximum and $\phi=90^{\circ}$ the minimum.

The conventional slat directivity for $\alpha_{\text {slat }}=30^{\circ}$ is shown in Fig. 7e. These data show a more complicated behavior. For a portion of the bandwidth, $\phi=124^{\circ}$ and $\phi=107^{\circ}$ are nearly equal in level. Additionally, the forward arc is computed as the directivity minimum for almost the whole frequency band of $10 \mathrm{kHz}$ to $30 \mathrm{kHz}$. These conventional slat data show a significant dependence of spectral level and directivity on slat angle, as reported by Mendoza et al. $\frac{8}{8}$ though the specific spectral level trends may not match. In general, slat angles further from the model chord line appear to shift the directivity peak from the forward to aft region of the model.

Krueger data in Fig. 7f] show similar trends to the conventional slat, although the aft-most measurement angle is still observed to be the directivity minimum. The $10^{\circ}$ and $20^{\circ}$ equivalent Krueger data show that a small $\alpha_{\text {Krueger }}$ shift can lead to a significant change in spectral behavior and directivity. The $30^{\circ}$ equivalent data appear to confirm this. Notably, the shedding peak for this final plot has more omnidirectional behavior, only reducing at $\phi=90^{\circ}$. As the gap and overlap are increased for this configuration, the data may show a reduction in aft shielding of the shedding peak (and associated resonance) noise source. Regarding Krueger rotation, as with the conventional slat, it appears that angles further from the model chord line shift the directivity peak from the forward to aft region of the model.

\section{III.D. Level comparison}

The calculated spectral levels of the conventional slat and equivalent-mission Krueger are now compared in Fig. 8, for a Mach number of $M=0.17$ and a measurement angle of $\phi=124^{\circ}$. Note that this comparison is not intended to show whether a Krueger flap is universally louder or more quiet than a conventional slat. This paper simply presents the spectral characteristics and differences of these particular devices.

The $\alpha_{\text {slat }}=10^{\circ}$ data and the Krueger equivalent are plotted in Fig. 8a For the region of the spectra not contaminated either by low frequency tones or a high frequency shedding peak, both devices show nearidentical spectral level and slope. This does not hold across different $\alpha_{\text {slat }}$ values. For $\alpha_{\text {slat }}=20^{\circ}$ in Fig. $8 \mathrm{~b}$, the conventional slat shows a small increase in level and a noticeable increase in spectral ripple. The Krueger flap, on the other hand, shows a more significant increase in level while maintaining a similar spectral shape (for uncontaminated frequencies). This trend continues for the $\alpha_{\text {slat }}=30^{\circ}$ data in Fig. $8 \mathrm{c}$. The overall trend is summarized in Fig. $8 \mathrm{~d}$. Here, $1 / 3^{\text {rd }}$-octave band differences are plotted for bands where no low frequency tones and no shedding peaks are present. The difference plot shows that the $\alpha_{\text {slat }}=10^{\circ}$ configuration will realize some acoustic improvement in the switch to an equivalent-mission Krueger, while the other two slat angles will not. As these data are near the directivity peaks for the $20^{\circ}$ and $30^{\circ}$ matching cases for both high-lift devices, this difference would appear to be due to more than a simple source rotation mismatch. Again, these data do not suggest that a Krueger is generally louder than a conventional slat. In fact, the opposite was shown by Pott-Pollenske et al. for a different Krueger design ${ }^{[3}$ These data do show that for various configurations, a given Krueger may be better or worse than an equivalent-mission conventional slat in terms of noise.

\section{Individual Configuration Perturbations}

The final section of this analysis focuses on individual configuration changes. These comparisons make no attempt to maintain matched aerodynamic behavior between the conventional slat and Krueger flap models. Instead the focus is on revisiting the behavior of conventional slat aeroacoustics for varying gap and overlap, along with addressing the effects of gap, overlap, and the Krueger cavity of Krueger flap aeroacoustics.

\section{IV.A. Conventional slat gap and overlap}

The influence of gap size on the conventional slat data is shown in Fig. 9. This plot shows the behavior of the data as the model gap is slowly closed while holding overlap constant. Referencing Fig. 2c this is done by traversing the slat vertically to the minimum non-zero gap value, prior to traversing it horizontally to close the gap with the slat trailing edge touching the main element leading edge. For the closed gap configuration, 


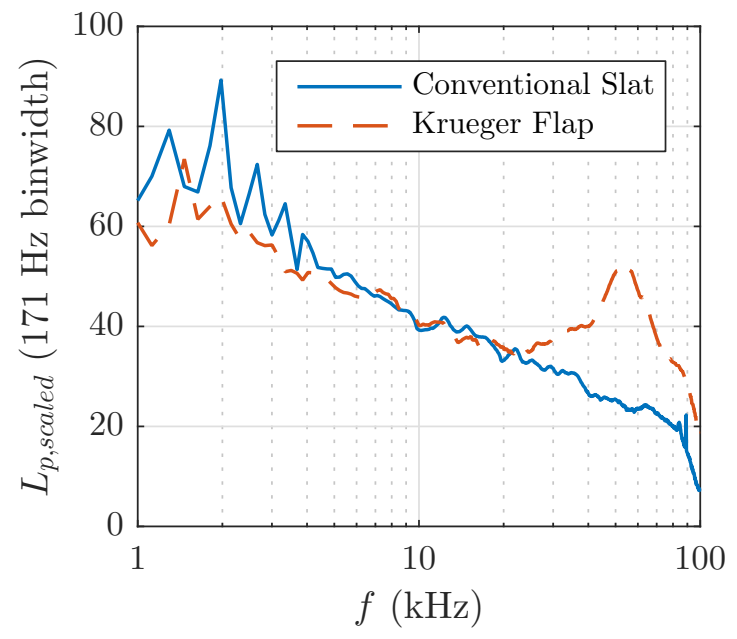

(a) $\alpha_{\text {slat }}=10^{\circ}$ narrowband

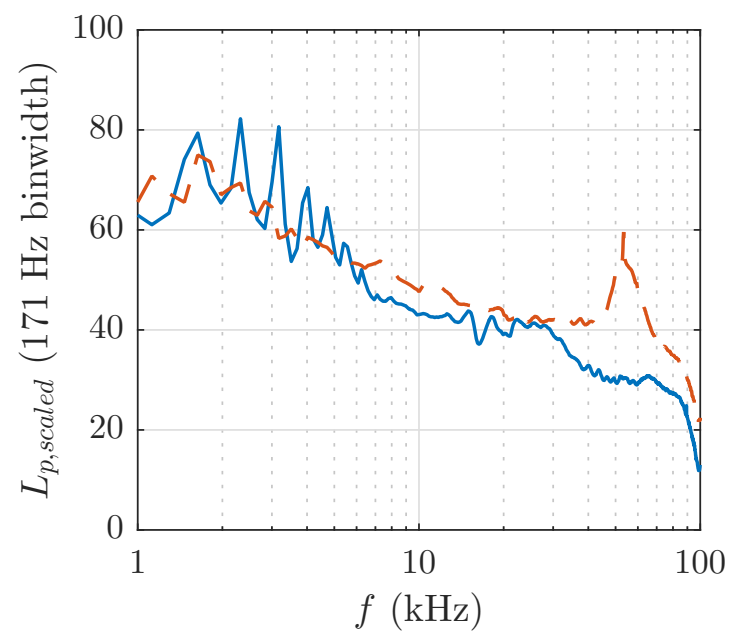

(c) $\alpha_{\text {slat }}=30^{\circ}$ narrowband

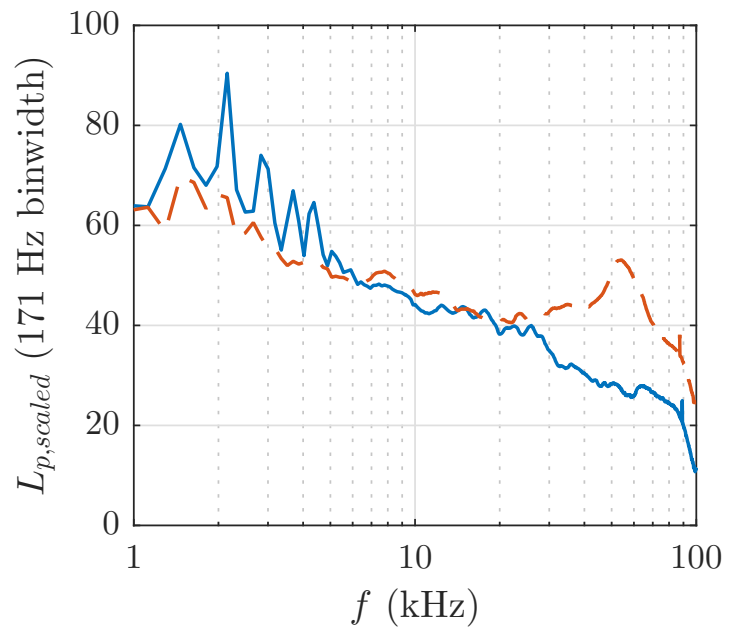

(b) $\alpha_{\text {slat }}=20^{\circ}$ narrowband

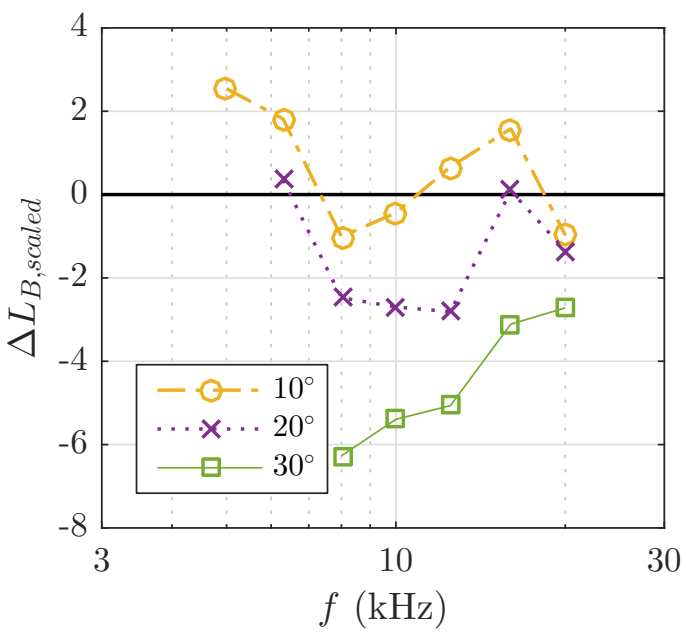

(d) $1 / 3^{\text {rd }}$-octave band differences

Figure 8. Comparison between conventional slat and equivalent-mission Krueger spectra, $M=0.17$ and $\phi=124^{\circ}$. For Fig. $8 \mathrm{~d}, \Delta L_{B, \text { scaled }}=L_{B, \text { scaled,Conventional }}-L_{B, \text { scaled,Krueger }}$.

the gap is also taped shut to ensure a seal. All data are shown for $\alpha_{\text {slat }}=30^{\circ}$. Due to slat support hardware constraints, the baseline $\alpha_{\text {slat }}=30^{\circ}$ gap and overlap values are not part of a constant-overlap traverse of the slat.

For all of the plotted angles, noise reduction is achieved at higher frequencies as the gap is reduced. This appears accentuated at the middle angles of $\phi=124^{\circ}$ and $\phi=107^{\circ}$ in Figs. 9b and 9c. A noise increase is observed between $6 \mathrm{kHz}$ and $10 \mathrm{kHz}$, especially at the aft directivity of $\phi=90^{\circ}$ in Fig. 9d. Comparison to examples from literature suggests that a reduction in noise should be observed when closing the gap $\stackrel{25}{2}$ but also that significant spectral variability may be present. A direct comparison is difficult as the particular gap values of this study differ from some of the previous work, $\frac{8}{8}$ but a clear conclusion (in agreement with previous work) is that the slat gap size has a strong influence on the acoustic signature, and this influence is directional.

For all of the plotted angles, reducing the slat gap (without closing it) strengthens the low frequency tones, with a particular tone level increase occurring for the tone closest to $2 \mathrm{kHz}$ in the plotted range. An odd spectral hump appears at higher frequencies for the larger two gap values. This may be the onset of a resonant amplification of a blunt shedding peak from the slat trailing edge. However, the frequency is somewhat low for such phenomena given the slat trailing edge thickness and expected gap velocities. Also the peak levels of this hump at lower Mach numbers are sufficiently close to the slat broadband levels that 


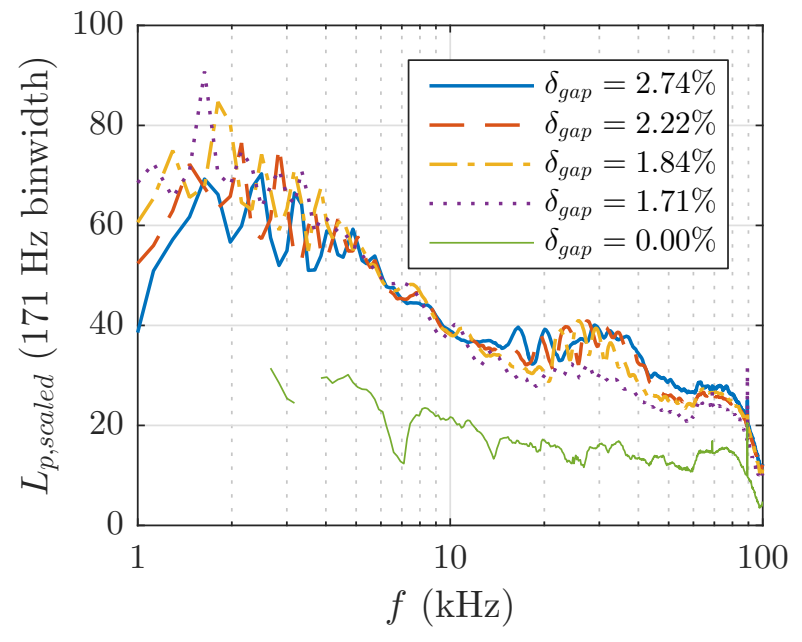

(a) $\phi=140^{\circ}$

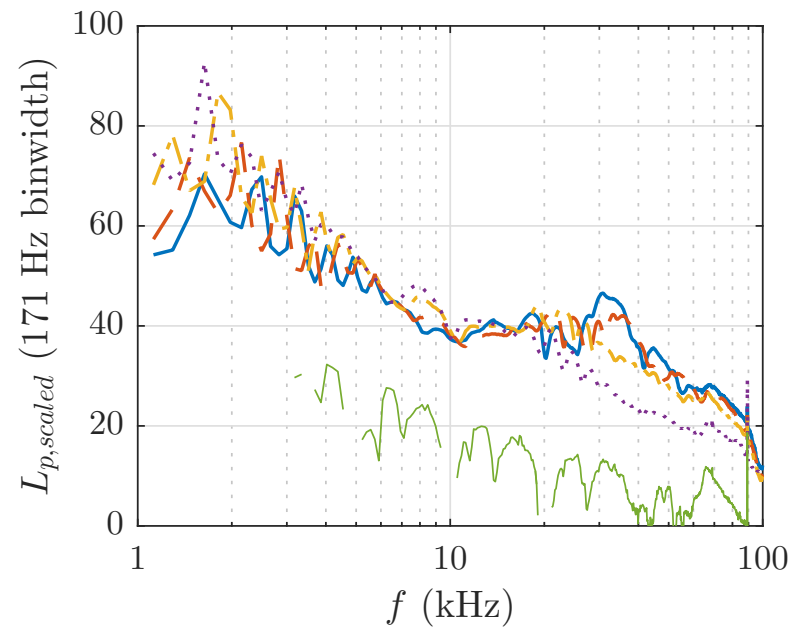

(c) $\phi=107^{\circ}$

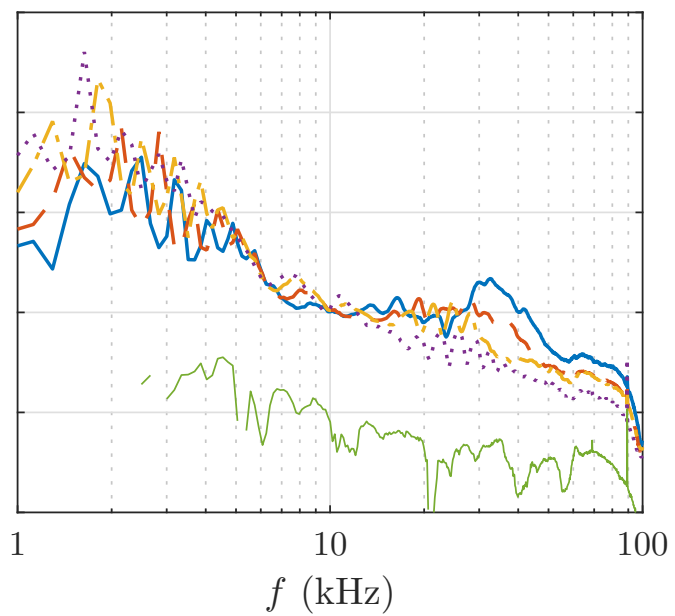

(b) $\phi=124^{\circ}$

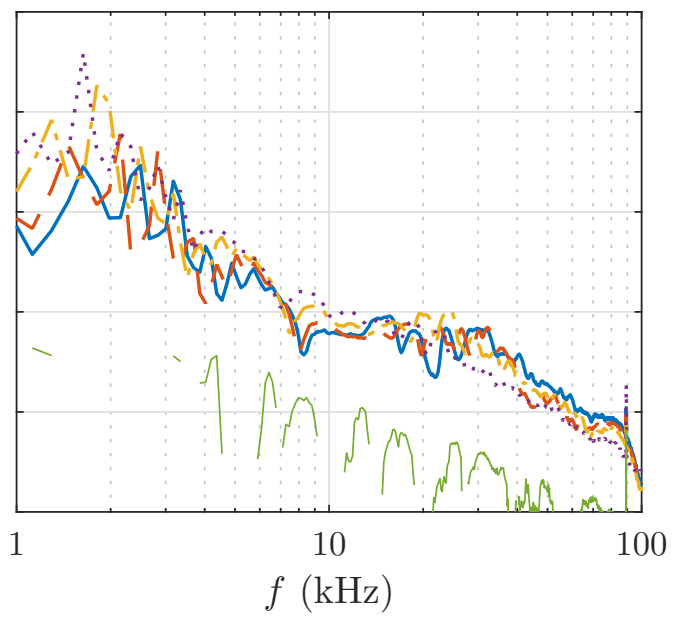

(d) $\phi=90^{\circ}$

Figure 9. Influence of slat gap, $M=0.17, \alpha_{\text {slat }}=30^{\circ}$ and $\delta_{\text {overlap }}=1.71 \%$ (except $\delta_{\text {overlap }}=0.00 \%$ for $\delta_{\text {gap }}=0.00 \%$ ).

clear Strouhal scaling is not discernable. As such, nothing conclusive is said about this spectral feature.

As in previous work, completely sealing the gap provides a dramatic reduction in the measured slat noise. The remaining slat noise becomes difficult to resolve in the deconvolution process, and some drop-out occurs in the results. This is likely because the signal-to-noise ratio of the slat sources to the sidewall junction sources drops dramatically. The spectra are plotted for the closed gap for qualitative discussion, providing a gross representation of the noise reduction potential of sealing the gap.

The influence of the slat overlap with the main element leading edge is shown in Fig. 10. This plot shows the behavior of the data as the overlap distance is slowly reduced while holding gap constant. Referencing Fig. 2c this is done by traversing the slat along an arc of constant offset from the main element surface. As with the gap study, these are all shown for $\alpha_{\text {slat }}=30^{\circ}$, and the baseline configuration is not included. Due to slat support hardware constraints, overlap values less than $\delta_{\text {overlap }}=-0.02 \%$ could not be achieved for the conventional slat model.

For $\phi=140^{\circ}$ in Fig. 10a, the data show little conclusive results or trends for the middle range of frequencies. Reducing the overlap first increases the spectral level slightly and then decreases it. More conclusive trends are evident for other directivities. For $\phi=124^{\circ}$ in Fig. 10b, reducing overlap at worst keeps the spectral levels the same in uncontaminated bands, while at best provides significant broadband reduction. Reducing overlap shows clear reduction in spectral levels for the other angles, at least for uncontaminated 


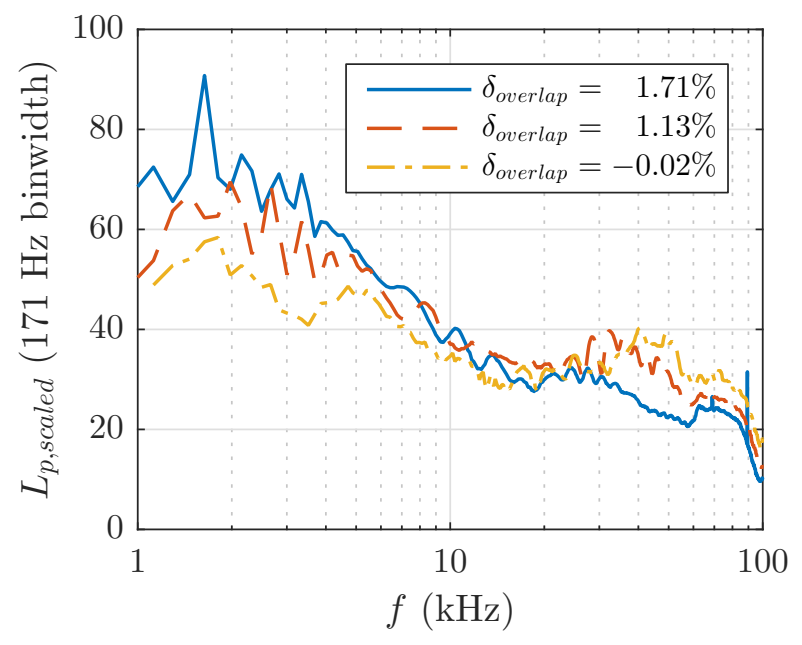

(a) $\phi=140^{\circ}$

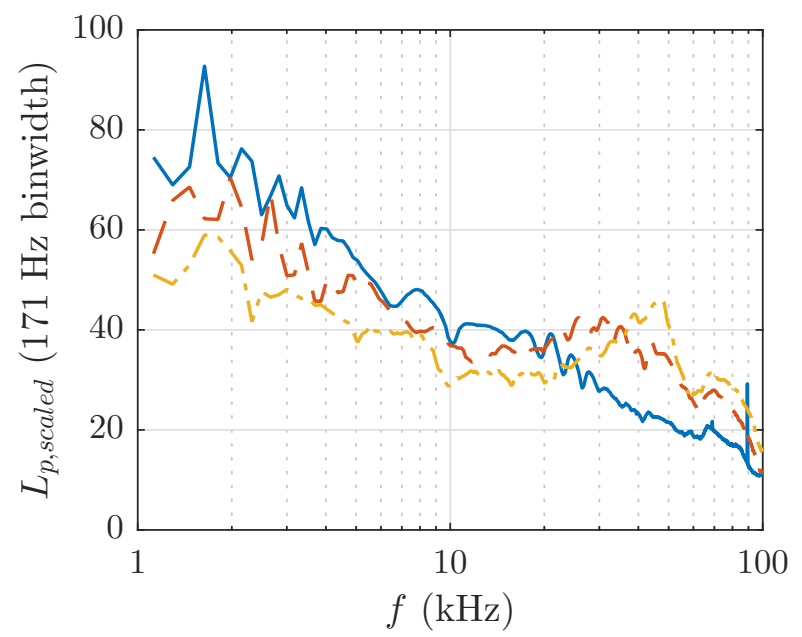

(c) $\phi=107^{\circ}$

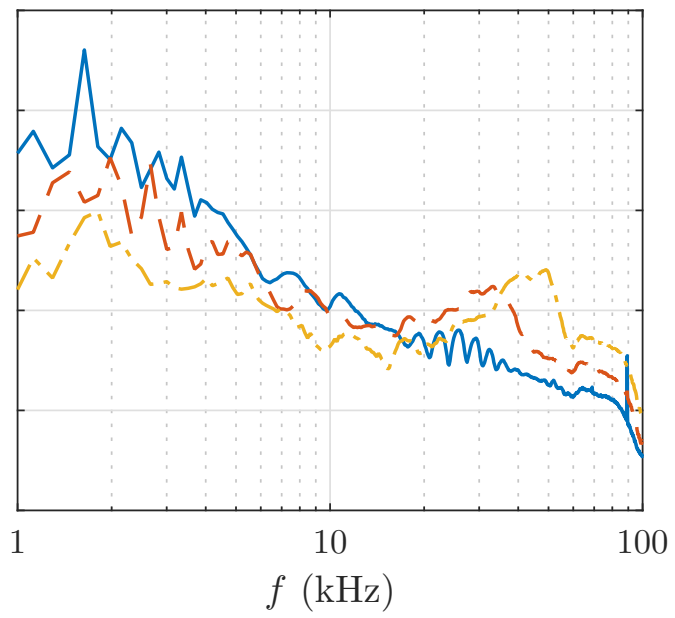

(b) $\phi=124^{\circ}$

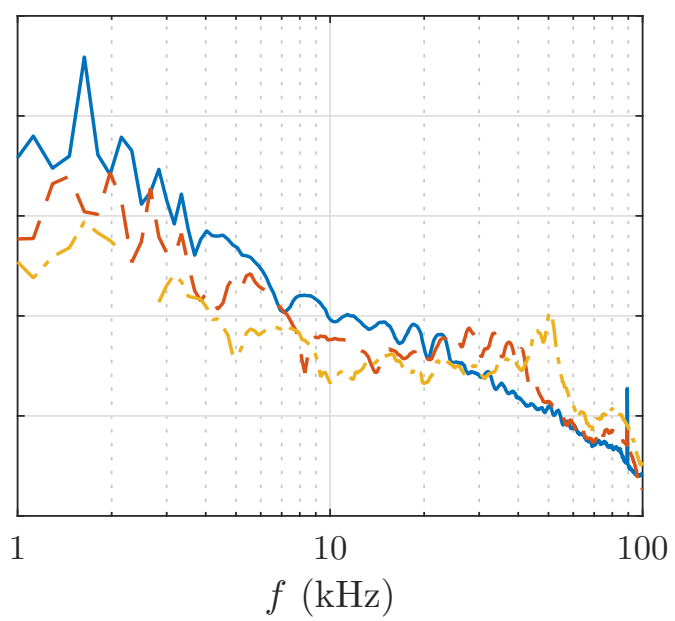

(d) $\phi=90^{\circ}$

Figure 10. Influence of slat overlap, $M=0.17$ and $\delta_{\text {gap }}=1.71 \%$.

frequencies. For low frequencies, reducing the overlap provides a strong reduction of the low frequency contaminating tones, suggesting overlap reduction can interfere with the feedback mechanisms that drive these. However, a trade-off occurs as overlap reduction leads to an increase in a high frequency hump in the data. Unlike with the gap variation data, this peak reaches a sufficient level that Strouhal scaling can be established, and at least for the $\delta_{\text {overlap }}=-0.02 \%$ data, the peak occurs at a frequency expected for trailing edge bluntness shedding. For this particular slat model, it appears that altering the overlap allows one model-scale contamination amplification mechanism to be exchanged for another.

\section{IV.B. Krueger flap gap and overlap}

The influence of gap size on the Krueger flap data is shown in Fig. 11. This plot shows the behavior of the data as the model gap is slowly closed while holding overlap constant, in the same fashion as was done with the conventional slat. Unlike with the conventional slat, the baseline $\alpha_{\text {slat }}=30^{\circ}$ equivalent Krueger configuration is part of this variation with $\delta_{g a p}=1.54 \%$. As with the conventional slat model, the gap is taped shut when it is closed $\left(\delta_{g a p}=0.00 \%\right)$.

For all of the plotted angles, noise increases for low-to-mid frequencies $(3 \mathrm{kHz}$ to $15 \mathrm{kHz})$ as the gap is reduced, similar to the conventional slat model but to a different degree. This is accentuated in the downstream direction. At higher frequencies, behavior of the broadband spectral levels is difficult to determine 
due to contamination of the blunt shedding peak. Reducing the gap reduces the strength of the low frequency tones for all directivities. Gap reduction first increases and then reduces both the frequency $(\sim 52$ $\mathrm{kHz}$ for $\delta_{\text {gap }}=1.54 \%$ and $\sim 40 \mathrm{kHz}$ for $\delta_{\text {gap }}=0.78 \%$ ) and strength of the trailing edge shedding peak. Both of these amplification mechanisms appear to be extremely dependent on specific details of the Krueger flap configuration. As with the conventional slat, closing the gap completely leads to a dramatic reduction in noise, and must be evaluated qualitatively due to limitations of the deconvolution process.

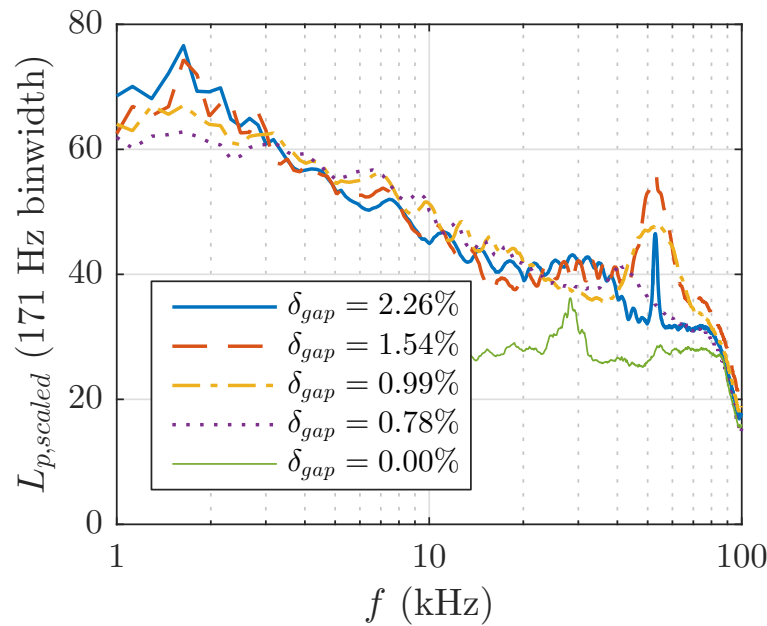

(a) $\phi=140^{\circ}$

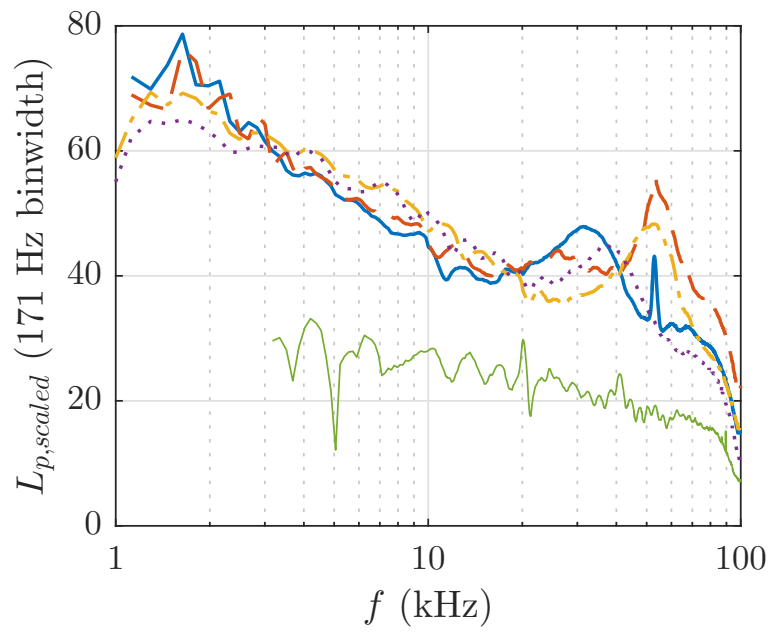

(c) $\phi=107^{\circ}$

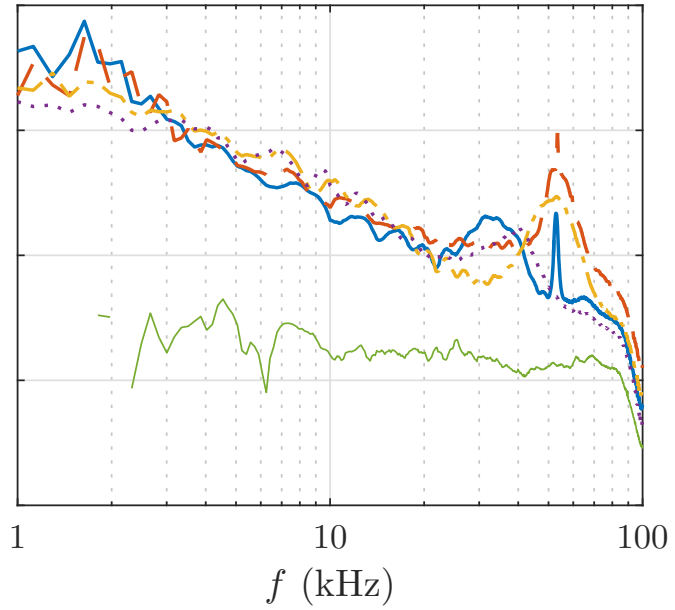

(b) $\phi=124^{\circ}$

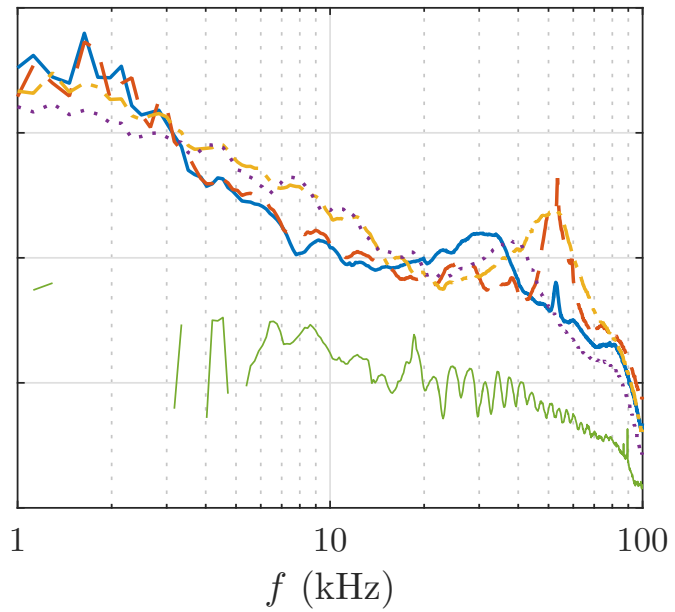

(d) $\phi=90^{\circ}$

Figure 11. Influence of Krueger gap, $M=0.17$ and $\delta_{\text {overlap }}=0.78 \%$ (except $\delta_{\text {overlap }}=0.00 \%$ for $\left.\delta_{\text {gap }}=0.00 \%\right)$.

The influence of the Krueger overlap with the main element leading edge is shown in Fig. 12. This plot shows the behavior of the data as the overlap distance is slowly reduced while holding gap constant, as was done with the conventional slat. Unlike the conventional slat, the baseline $\alpha_{\text {slat }}=30^{\circ}$ equivalent Krueger configuration is part of this variation with $\delta_{\text {overlap }}=0.78 \%$. Also unlike with the conventional slat, more negative values of overlap are possible with the Krueger support hardware.

The forward angles in Figs. 12a and 12b show similar behavior. Mid-frequency levels increase from a minimum for the largest overlap to a peak as the overlap approaches zero, before reducing again as the overlap becomes more negative. High frequency broadband behavior is difficult to assess due to the presence of the shedding peaks. Lower frequencies (uncontaminated by low frequency tones) show a more complicated behavior at the middle two overlap values, but overall have a decrease from the largest positive overlap to the most negative overlap. This behavior affects a broader range of the spectrum as the directivity angle 
shifts downstream of the model. Sufficient overlap reduction appears to mitigate the low frequency tones, as it did for the conventional slat. Overlap reduction also increases the strength of the shedding peak to a point, but sufficient overlap reduction to the point of larger negative overlap values eliminates the shedding peak. The negative-most overlap values appear to have mitigated both the low frequency tone and the high frequency shedding peak contributions to the spectra. Possible acoustic causes for these complicated spectral shifts may include such things as changes in source orientation, or partial source shielding by the Krueger flap or main element. However, significant changes to the flow around the model are observed in the static pressure measurements. This would indicate changes to the sources themselves, so it is difficult to formulate a comprehensive hypothesis without more data on the Krueger cove and gap flow fields.

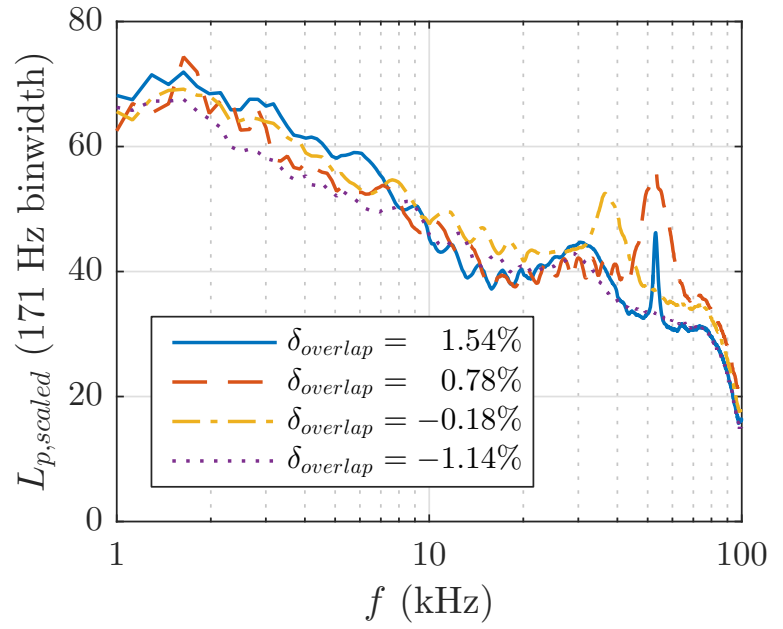

(a) $\phi=140^{\circ}$

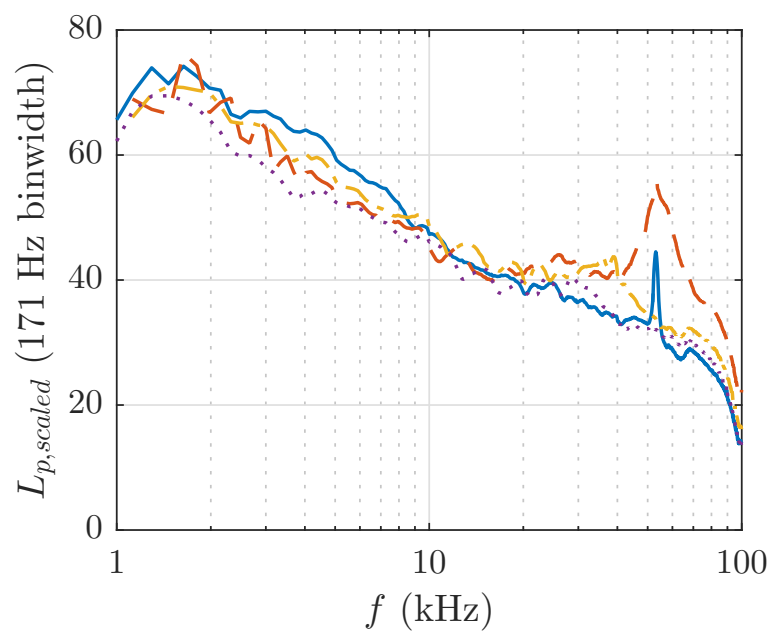

(c) $\phi=107^{\circ}$

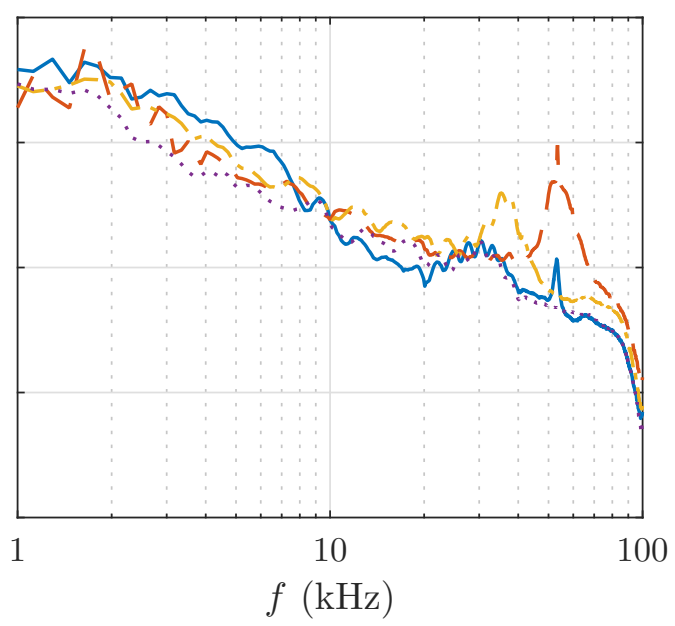

(b) $\phi=124^{\circ}$

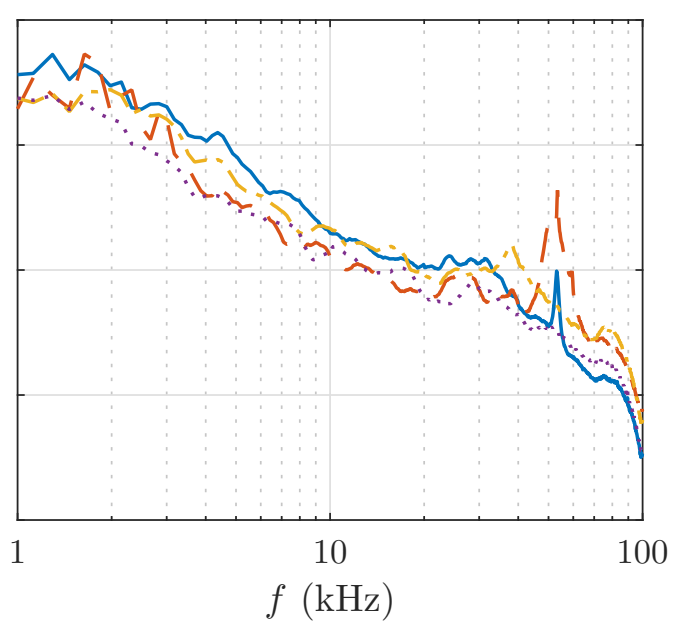

(d) $\phi=90^{\circ}$

Figure 12. Influence of Krueger overlap, $M=0.17$ and $\delta_{\text {gap }}=1.54 \%$.

\section{IV.C. Krueger cavity}

The final parameter variation considered is the influence of a simplified cavity on the Krueger model noise. All of the results presented so far have been with the model cavity closed. The cavity, incorporated as a simplified rectangular cut-out, was opened and data re-acquired for several configurations. The baseline $\alpha_{\text {slat }}=30^{\circ}$ Krueger equivalent is shown in Fig. 13 , for $M=0.17$.

Overall, the Krueger cavity has a small influence on the model noise at upstream angles plotted in Figs. $13 \mathrm{a}$ and 13b Some minor reduction in low frequency tone level is observed in some cases. Broadband levels slightly increase at higher frequencies prior to the onset of the shedding peak. Interestingly, the 
shedding peak level does show some reduction at these upstream angles. The peak reduction becomes less noticeable as the angles shift downstream in Figs. 13c and 13d. At these downstream angles, the broadband level increase at higher frequencies goes away, and is replaced by a broadband level reduction at lower frequencies. This reduction is more pronounced with the $\phi=90^{\circ}$ data. It is difficult to hypothesize about a possible cause for this reduction without more information on the flow field in the vicinity of the cavity, though static pressure data suggest a minor influence on the global flow field around the Krueger flap and main element leading edge, suggesting a possible change to the other Krueger flap noise source mechanisms when the cavity is opened.

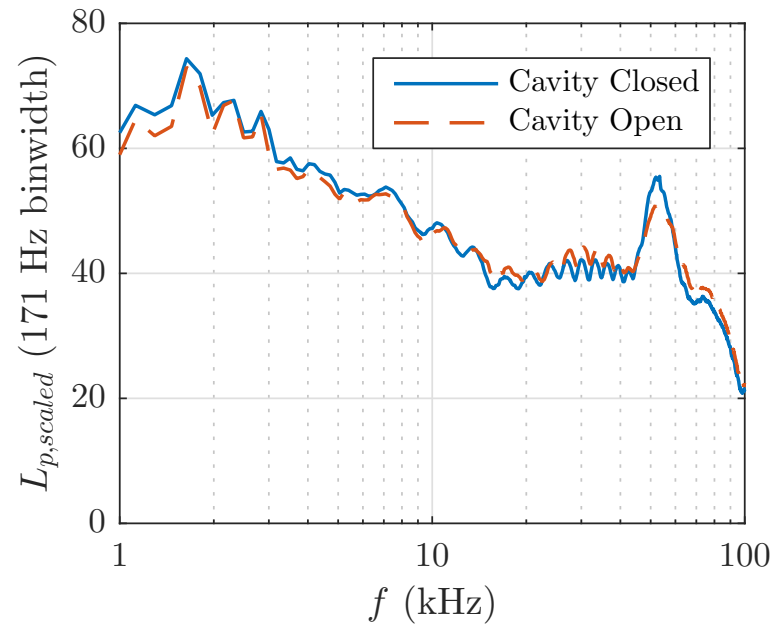

(a) $\phi=140^{\circ}$

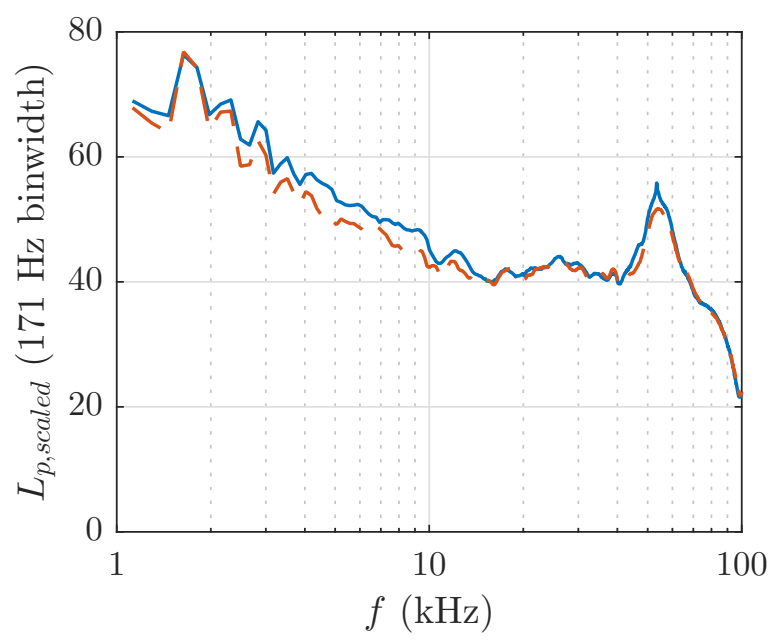

(c) $\phi=107^{\circ}$

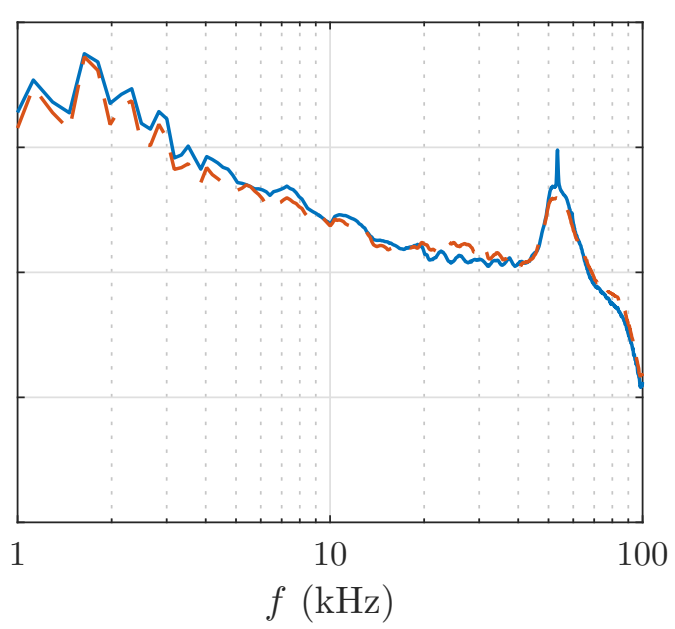

(b) $\phi=124^{\circ}$

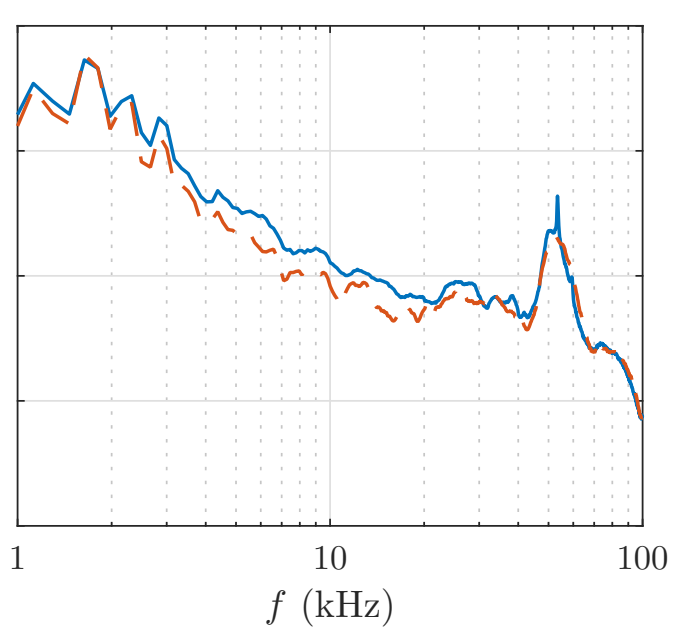

(d) $\phi=90^{\circ}$

Figure 13. Influence of Krueger cavity, $M=0.17$.

\section{Summary and Conclusions}

An experiment comparing the acoustic behavior of a conventional slat to an equivalent-mission Krueger flap has been conducted, and results are presented. The experiment utilized a companion CFD effort to compare the conventional slat to a Krueger, which could provide the same lift at the same AoA under free stream flight for a common reference cruise airfoil. This companion CFD effort also related free stream flight conditions to open jet wind tunnel conditions to provide a linkage between an in-tunnel slat and an in-tunnel Krueger.

Direct comparison is made between these equivalent-mission high-lift devices at appropriate deployment 
settings. As with other small-scale slat noise experiments, full-scale comparison is complicated by the presence of contaminating sources in the data. Strong low frequency tones are present, which do not appear in full-scale measurements. For the Krueger, a strong high frequency shedding peak is observed. This peak occurs at an equivalent full-scale frequency that is lower than it should be due to the relative thickness of the model trailing edges. A perfectly-scaled model would have a thinner trailing edge, leading to a higher-frequency shedding peak. Nevertheless, common behavior is observed between the conventional slat and Krueger for both the contaminating sources and the desired broadband spectral components. Overall spectral scaling follows a $M^{4.5}$ power law when evaluated as a function of $S t$ for both devices, in agreement with previous studies. Spectral scaling as a function of fixed frequency, as a surrogate for Helmholtz number, shows expected behavior. Model directivity is not fully consistent with previous slat noise studies, but the trends between the conventional slat and Krueger are extremely similar. For this particular configuration, the Krueger flap is slightly louder than the conventional slat, but this says nothing conclusive about Krueger flap noise in general.

Individual parameter variations are performed on the models to assess the acoustic influence of the gap and overlap of both the conventional slat and Krueger flap. Reducing the gap shows an increase in low- to mid-frequency levels for both models. It shows a reduction in high-frequency levels for the conventional slat. The Krueger flap shedding peak makes it difficult to assess high-frequency trends in the gap reduction study. For both models, completely sealing the gap leads to a dramatic reduction in acoustic levels, consistent with previous studies. Overlap reduction appears to have an opposite influence on the Krueger data when compared to the conventional slat, but this comparison is limited as the conventional slat mounting hardware prevented sizable negative overlap values. This relationship is band-dependent and, due to strong shedding peak contamination, warrants further investigation. The final parameter variation, the Krueger cavity, has a frequency-dependent impact on both acoustic level and directivity of the Krueger flap model. This impact is observable, but less dramatic than the impact of other variations in the Krueger configuration.

Overall, while the spectra of the conventional slat are different when compared to the Krueger flap, the behavior of the two devices is similar as various parameters are varied. Trends of the broadband, uncontaminated levels are in agreement with every scaling attempt and parameter shift, aside from possibly the slat/Krueger overlap. Results suggest that a Krueger flap noise model should be similar to a conventional slat noise model, with the inclusion of an appropriate term for the Krueger cavity. Further understanding of the low frequency tone and high frequency shedding peak amplification mechanisms is necessary to design improved model-scale experiments to measure broadband slat noise.

\section{Acknowledgments}

This work was funded by the NASA ERA Project. The authors wish to acknowledge the efforts of the QFF team: Dan Stead, Jaye Moen, and Dennis Kuchta. Additionally, they wish to acknowledge the efforts of the NASA Ames Applied Modeling and Simulation Branch headed by Cetin Kiris, in particular the input of both Cetin Kiris and Dogus Akaydin. Finally, they acknowledge the invaluable input of Yueping Guo in this work.

\section{References}

${ }^{1}$ Collier, F. S., Thomas, R. H., Nickol, C. L., Lee, C. M., and Tong, M., "Environmentally Responsible Aviation - Real Solutions for Environmental Challenges Facing Aviation," Paper No. 802, 27 $7^{\text {th }}$ International Congress of the Aeronautical Sciences, Nice, France, 19 - 24 September 2010.

${ }^{2}$ Strüber, H. and Wild, J., "Aerodynamic Design of a High-Lift System Compatible with a Natural Laminar Flow Wing within the DeSiReH Project," ISBN 3-932182-80-4, 29 $9^{\text {th }}$ Congress of the International Council of the Aeronautical Sciences, St. Petersburg, Russia, 7-12 September 2014.

${ }^{3}$ Pott-Pollenske, M., Almoneit, D., and Wild, J., "On the Noise Generation of Krueger Leading Edge Devices," AIAA 2015-3142, 21 ${ }^{\text {st }}$ AIAA/CEAS Aeroacoustics Conference, Dallas/Ft. Worth, TX, 2015.

${ }^{4}$ Humphreys, W. M. and Brooks, T. F., "Noise Spectra and Directivity For a Scale-Model Landing Gear," AIAA 2007-3458, $13^{\text {th }}$ AIAA/CEAS Aeroacoustics Conference, Rome, Italy, 2007.

${ }^{5}$ Guo, Y., Burley, C. L., and Thomas, R. H., "Modeling and Prediction of Krueger Device Noise," accepted, $22^{\text {nd }}$ AIAA/CEAS Aeroacoustics Conference, Lyon, France, 2016.

${ }^{6}$ Burnside, N. J., Horne, W. C., Elmer, K. R., Cheng, R., and Brusniak, L., "Phased Acoustic Array Measurements of a $5.75 \%$ Hybrid Wing Body Aircraft," AIAA 2016-0012, 54 $4^{\text {th }}$ AIAA Aerospace Sciences Meeting, San Diego, CA, 2016.

${ }^{7}$ Choudhari, M. and Lockard, D. P., "Assessment of Slat Noise Predictions for 30P30N High-Lift Configuration from BANC-III Workshop," AIAA 2015-2844, 21 ${ }^{\text {st }}$ AIAA/CEAS Aeroacoustics Conference, Dallas/Ft. Worth, TX, 2015. 
${ }^{8}$ Mendoza, J. M., Brooks, T. F., and Humphreys, W. M., "An aeroacoustic study of a leading edge slat configuration," International Journal of Aeroacoustics, Vol. 1, No. 3, 2002, pp. 241-274.

${ }^{9}$ Turner, T. L., Kidd, R. T., Hartl, D. J., and Scholten, W. D., "Development of a SMA-Based, Slat-Cove Filler for Reduction of Aeroacoustic Noise Associated with Transport-Class Aircraft Wings," SMASIS2013-3100, Proceedings of the ASME 2013 Conference on Smart Materials, Adaptive Structures and Intelligent Systems, Snowbird, UT, 2013.

${ }^{10}$ Akaydin, H. D., Housman, J. A., Kiris, C. C., Bahr, C. J., and Hutcheson, F. V., "Krueger flaps revisited: a computational assessment for next-generation airliners," accepted, 22 ${ }^{\text {nd }}$ AIAA/CEAS Aeroacoustics Conference, Lyon, France, 2016.

${ }^{11}$ Housman, J. A. and Kiris, C. C., "Slat Noise Predictions using the Overset Grid Approach and Higher-Order Finite Difference Methods," accepted, $22^{\text {nd }}$ AIAA/CEAS Aeroacoustics Conference, Lyon, France, 2016.

${ }^{12}$ Amiet, R. K., "Refraction of sound by a shear layer," Journal of Sound and Vibration, Vol. 58, No. 4, 1978 , pp. 467-482.

${ }^{13}$ Jiao, J., Delfs, J. W., and Dierke, J., "Towards CAA based Acoustic Wind Tunnel Corrections for Realistic Shear Layers," AIAA 2015-3278, 21 $1^{\text {st }}$ AIAA/CEAS Aeroacoustics Conference, Dallas/Ft. Worth, TX, 2015.

${ }^{14}$ Humphreys, W. M., Brooks, T. F., Hunter, W. W., and Meadows, K. R., "Design and Use of Microphone Directional Arrays for Aeroacoustic Measurements," AIAA-98-0471, 36th AIAA Aerospace Sciences Meeting \& Exhibit, Reno, NV, January 1998.

${ }^{15}$ Brooks, T. F. and Humphreys, W. M., "A deconvolution approach for the mapping of acoustic sources (DAMAS) determined from phased microphone arrays," Journal of Sound and Vibration, Vol. 294, 2006, pp. 856-879.

${ }^{16}$ Bahr, C. J., Brooks, T. F., Humphreys, W. M., Spalt, T. B., and Stead, D. J., "Acoustic Data Processing and Transient Signal Analysis for the Hybrid Wing Body 14- by 22-Foot Subsonic Wind Tunnel Test," AIAA 2014-2345, 20 $0^{\text {th }}$ AIAA/CEAS Aeroacoustics Conference, AIAA Aviation 2014, Atlanta, GA, June 2014.

${ }^{17}$ Imamura, T., Ura, H., Yokokawa, Y., and Yamamoto, K., "A Far-field Noise and Near-field Unsteadiness of a Simplified High-lift-configuration Model (Slat)," AIAA 2009-1239, 47 ${ }^{\text {th }}$ AIAA Aerospace Sciences Meeting, Orlando, FL, 2009.

${ }^{18}$ Pott-Pollenske, M., Delfs, J., and Reichenberger, J., "A Testbed for large scale and high Reynolds number Airframe Noise Research," AIAA 2013-2260, 19 ${ }^{\text {th }}$ AIAA/CEAS Aeroacoustics Conference, Berlin, Germany, 2013.

${ }^{19}$ Pascioni, K. A., Cattafesta, L. N., and Choudhari, M. M., "An Experimental Investigation of the 30P30N Multi-Element High-Lift Airfoil," AIAA 2014-3062, 20 ${ }^{\text {th }}$ AIAA/CEAS Aeroacoustics Conference, Atlanta, GA, 2014.

${ }^{20}$ Khorrami, M. R., Berkman, M. E., and Choudhari, M. M., "Unsteady Flow Computations of a Slat with a Blunt Trailing Edge," AIAA Journal, Vol. 38, No. 11, November 2000, pp. 2050-2058.

${ }^{21}$ Choudhari, M. M., Lockard, D. P., Macaraeg, M. G., Singer, B. A., Streett, C. L., Neubert, G. R., Stoker, R. W., Underbrink, J. R., Berkman, M. E., Khorrami, M. R., and Sadowski, S. S., "Aeroacoustic Experiments in the Langley LowTurbulence Pressure Tunnel," Tech. Rep. NASA TM-2002-211432, NASA, 2002.

${ }^{22}$ Dobrzynski, W. and Pott-Pollenske, M., "Slat Noise Source Studies for Farfield Noise Prediction," AIAA 2001-2158, $7^{\text {th }}$ AIAA/CEAS Aeroacoustics Conference, Maastricht, The Netherlands, 2001.

${ }^{23}$ Guo, Y., "Aircraft Slat Noise Modeling and Prediction," AIAA 2010-3837, 16th AIAA/CEAS Aeroacoustics Conference, Stockholm, Sweden, 2010.

${ }^{24}$ Spalart, P. R., "On the precise implications of acoustic analogies for aerodynamic noise at low Mach numbers," Journal of Sound and Vibration, Vol. 332, 2013, pp. 2808-2815.

${ }^{25}$ Pott-Pollenske, M., Alvarez-Gonzalez, J., and Dobrzynski, W., "Effect of Slat Gap on Farfield Radiated Noise and Correlation with Local Flow Characteristics," AIAA 2003-3228, $9^{\text {th }}$ AIAA/CEAS Aeroacoustics Conference, Hilton Head, SC, 2003. 